Cell Calcium 96, June 2021, 102384

https://doi.org/10.1016/j.ceca.2021.102384

https://www.sciencedirect.com/science/article/pii/S0143416021000385\#fig0030

\title{
SK4 oncochannels regulate calcium entry and promote cell migration in KRAS-mutated colorectal cancer
}

Sajida Ibrahim ${ }^{1, \#}$, Justine Chaigne ${ }^{1,2}$, Hassan Dakik ${ }^{1,3}$, Yann Fourbon ${ }^{2}$, Laetitia Corset ${ }^{1,3}$, Thierry Lecomte ${ }^{1,4}$, William Raoul ${ }^{2, *}$ and Maxime Guéguinou ${ }^{1, *}, \#$

${ }^{1}$ Université de Tours, EA 7501 GICC, Tours, France.

${ }^{2}$ Université de Tours, Inserm, UMR 1069, Nutrition Croissance et Cancer (N2C), Faculté de Médecine, Tours, France.

${ }^{3}$ CNRS ERL 7001 LNOx, Tours France.

${ }^{4}$ CHRU de Tours, Department of Hepato-Gastroenterology and Digestive Oncology, France.

* these senior authors contributed equally

\# Corresponding Authors

Dr Maxime Guéguinou, Université de Tours, 10 boulevard Tonnellé, 37032 Tours, France. Tel: +33(0)247366267. Email address: maxime.gueguinou@univ-tours.fr and Dr Sajida Ibrahim, Mcgill university, McGill University, RI-MUHC, Glen Site, 1001 Décarie Boulevard, Montreal, Quebec, Canada, H4A3J1. Email address: sajida.ibrahim@mail.mcgill.ca

\section{Novelty \& Impact}

For the first time to our knowledge, this article presents SK4 as an oncochannel and a potential therapeutic target in $K R A S$-mutated colorectal cancer (CRC). Based on experimental findings and transcriptomic analysis, we highlight SK4 as a major contributor to cell migration and 
invasion by modulating both calcium and ROS signaling in $K R A S$-mutated CRC. In this setting, SK4 could be a potential target to reduce metastasis.

Running title: SK4 channel and colorectal cancer

Keywords: SK4, KCa3.1, calcium signaling, colorectal cancer, KRAS, migration

\begin{abstract}
Background: Colorectal cancer (CRC) metastases are the main cause of CRC mortality. Intracellular $\mathrm{Ca} 2+$ regulates cell migration and invasion, key factors for metastases. $\mathrm{Ca} 2+$ also activates $\mathrm{Ca} 2+-$ dependent potassium channels which in turn affect $\mathrm{Ca} 2+$ driving force. $\mathrm{We}$ have previously reported that the expression of the $\mathrm{Ca} 2+$ activated potassium channel $K C N N 4$ (SK4) is higher in CRC primary tumors compared to normal tissues. Here, we aimed to investigate the role of SK4 in the physiology of CRC.
\end{abstract}

Results: SK4 protein expression is enhanced in CRC tissues compared to normal colon tissues, with a higher level of KCNN4 in CRC patients with KRAS mutations. At the cellular level, we found that SK4 regulates the membrane potential of HCT116 cells. We also found that its inhibition reduced store operated $\mathrm{Ca} 2+$ entry $(\mathrm{SOCE})$ and constitutive $\mathrm{Ca} 2+$ entry $(\mathrm{CCE})$, while reducing cell migration. We also found that the activity of SK4 is linked to resistance pathways such as KRAS mutation and the expression of NRF2 and HIF-1 $\alpha$. In addition, the pharmacological inhibition of SK4 reduced intracellular reactive oxygen species (ROS) production, NRF2 expression and HIF1 $\alpha$ stabilization.

Conclusion: Our results suggest that SK4 contributes to colorectal cancer cell migration and invasion by modulating both $\mathrm{Ca} 2+$ entry and ROS regulation. Therefore, SK4 could be a potential target to reduce metastasis in $K R A S$-mutated CRC. 


\section{Introduction}

Despite advances in detection techniques and the emergence of targeted treatments, colorectal cancer (CRC) remains the second leading cause of cancer-related death and the third most common cancer worldwide. Metastatic spread is the main cause of CRC mortality with a 5-year overall survival rate of $14 \%$ for patients with distant metastases ("Key Statistics for Colorectal Cancer" n.d.). Cell migration and invasion are key biological processes for metastasis development, and increasing evidence suggests that these cancer "Hallmarks" are promoted by altered $\mathrm{Ca} 2+$ signaling [1].

Calcium-dependent potassium channels $(\mathrm{KCa})$ play a crucial role in cell migration and cell proliferation by hyperpolarizing plasma membrane leading to an increase of $\mathrm{Ca} 2+$ driving force . The family of $\mathrm{KCa}$ is formed by three subtypes, divided according to their conductance: 1) small conductance (SK1, SK2 and SK3); 2) intermediate conductance (SK4/IKCa); and 3) big conductance $(\mathrm{BKCa})$. Of note, the activity of $\mathrm{KCa}(\mathrm{s})$ was reported in the proliferation, migration and metastasis development of prostate [2] and breast cancers [3]. In CRC, $\mathrm{KCa}(\mathrm{s})$ interact with $\mathrm{Ca} 2+$ channels (such as Orai1 and TRPC1) to increase $\mathrm{Ca} 2+$ entry and promote cellular functions, such as proliferation and migration [4],[5, 6]. We recently reported that SK4 expression is induced in CRC compared to adjacent normal tissue [7]. Yet, little is known about the role of SK4 in CRC development and tumorigenesis.

SK4, also named KCa3.1, Gardos channel or IK1, is formed by tetrameric subunit of SK4 protein encoded by KCNN4 gene. Membrane expression of SK4 channel, its assembly and $\mathrm{Ca} 2+$ detection are conferred by calmodulin [8]. The inhibition of SK4 was found to reduce the growth of pancreatic cancer cells [9], and it was proposed as potential therapeutic target to overcome radiotherapy-resistance in glioblastoma [10].

In the present study, we aimed to explore the function of SK4 channel in CRC, and to investigate its impact on $\mathrm{Ca} 2+$ entry. We found that SK4 is highly expressed in primary and metastatic CRC samples, and is even more increased in tumors harboring KRAS mutations. Our data showed that SK4 is an important contributor to CRC cell migration in KRAS-mutated cells, and regulates membrane potential and cytosolic $\mathrm{Ca} 2+$ concentration by modulating both storeindependent and store-dependent $\mathrm{Ca} 2+$ entry. The interplay between $\mathrm{Ca} 2+$ and reactive oxygen species (ROS) signaling pathways plays a crucial role in controlling several cancer processes. In addition, we found that SK4 inhibition reduced intracellular reactive oxygen species (ROS) 
production, NRF2 expression and HIF1 $\alpha$ stabilization. These latter features could also be linked with modulation of migration or invasion [11].

\section{Materials and methods}

\section{Cell culture}

HCT116 (RRID:CVCL_0291), LoVo (RRID:CVCL_0399), SW480 (RRID:CVCL_0546), HT29 (RRID:CVCL_0320) and SW48 (RRID:CVCL_1724) cells were purchased from ATCC. Cell lines were maintained in McCoy's medium (Gibco, ThermoFisher, Illkirch, France) supplemented with $10 \%$ fetal bovine serum, without antibiotics at $37^{\circ} \mathrm{C}$ and $5 \% \mathrm{CO}_{2}$. Mycoplasma absence was regularly tested using PlasmoTest kit (HEK blue, Invivogen, Toulouse, France).

\section{Drugs and reagents}

SK4 inhibitors: TRAM-34 (100 nM) was purchased from Sigma-Aldrich (Merck, Darmstadt, Germany). Charybdotoxin (100 nM) was purchased from Smartox (Saint Egrève, France), 2 APB $(100 \mu \mathrm{M})$ and SKF96365 $(40 \mu \mathrm{M})$ were purchased from Sigma; Synta66 (GLXC03244, $10 \mu \mathrm{M}$ ) was purchased from Glixx Laboratories Inc (Hopkinton, MA, USA).siKRAS and siKCNN4 were purchased from Interchim.

\section{Reverse transcription and Real-time quantitative PCR}

Total RNA was collected using Nucleospin RNA kit (Macherey-Nagel, France) and transcribed into cDNA with GoScript Reverse Transcription System (Promega, Madison, WI, USA). cDNA was then amplified with SYBR Green Master kit (Roche, Mannheim, Germany) using a Light Cycler 480 apparatus. PCR reactions were performed in 40 cycles of $15 \mathrm{~s}$ at $95{ }^{\circ} \mathrm{C}, 45 \mathrm{~s}$ at 60 ${ }^{\circ} \mathrm{C}$. Relative quantification gene expression was evaluated by the $2^{-\Delta \Delta \mathrm{Ct}}$ method with respect to the housekeeping gene HPRT1. The primers sequences used are: HPRT1: forward 5' CATTAT-GCT-GAG-GAT-TTG-GAA-AGG 3' reverse 5' CTT-GAG-CAC-ACA-GAG-GGCTAC-A 3'; KCNN4 : forward 5' CTG-CCT-GTG-CAC-TGG-AGT-C 3' reverse 5' CGT-GCTTCT-CTG-CCT-TGT-TA 3'; KRAS : forward 5' TTG-TGG-ACG-AAT-ATG-ATC-CAA-C 3' reverse. 5' TCC-CTC-ATT-GCA-CTG-TAC-TCC 3'.

\section{RNA interference:}

Twenty-four hours before transfection, cells were seeded at 300,000 cells/well in 6-well plates. The next day, cells were transfected with siRNAs targeting SK4 (OriGene Technologies, MD, USA) or KRAS (OriGene Technologies,MD, USA)) using lipofectamine (RNAiMax reagent, 
Invitrogen) according to the supplier's instructions. Scrambled siRNA was used as negative control.

siSK4 sequences:

(A) 5' AUGGaUAUCCAGUAUACCAAAGAGA 3',

(B) 5' GGCCAAGCUUUACAUGAACACGCAC 3'

(C) 5' GGCUACUUUCCCCAGUACUGAGGTG 3'

siKRAS sequences:

(A) 5' GCAUGAAUUCUGCAUUGAGAAACTG 3'

(B) 5' CGAUACAGCUAAUUCAGAAUCAUTT 3'

siOrai1 sequence: 5' GCCATAAGACGGACCGACA 3'

siTRPC1 sequence: reference sc-42664 (Santa Cruz)

\section{Cell migration and invasion assays}

Migration was evaluated using 24 well plates provided with 8 - $\mu \mathrm{m}$ pore size polyethylene terephthalate membrane cell culture inserts (BD, Rungis, France). Inserts were coated with bovine fibronectin 1/300 (Sigma-Aldrich). HCT116 were seeded 70000 per insert in the upper chamber. After $24 \mathrm{~h}$, stationary cells were removed from the top side of the membrane, whereas migrated cells in the bottom side of the inserts were fixed and stained with DAPI and counted in five different fields (magnification, $\times 200$ ). At least three independent experiments were each performed in triplicate.

Invasion was evaluated using 24 well plates provided with 8 - $\mu \mathrm{m}$ pore size Inserts coated with matrigel (BD BioCoat). HCT116 were seeded 80000 cells/insert. After 24 h, stationary cells were removed from the top side of the membrane, whereas invading cells in the bottom side of the inserts were fixed and stained with DAPI and counted in five different fields (magnification, $\times 200$ ). At least three independent experiments were each performed in duplicate.

\section{Flow cytometry analysis}

Cell cycle: Cells were harvested by trypsin-EDTA $24 \mathrm{~h}$ after treatments, washed in PBS 1x, fixed in cold $70 \%$ ethanol and incubated at $-20^{\circ} \mathrm{C}$ for at least 2 hours, then suspended in PBS 
with RNase and stained with $0.025 \mathrm{mg} / \mathrm{mL}$ Propidium Iodide for $30 \mathrm{~min}$ in the dark at room temperature. DNA content of stained cells was analyzed using a Gallios flow cytometer (Beckman Coulter, Villepinte, France). For each sample, a minimum of $5 \times 10^{4}$ cells was evaluated. Analyses were done using Kaluza software 1.3 (Beckman Coulter).

Apoptosis: Cells were harvested by Accutase, washed by PBS 1x and then resuspended in annexin binding buffer following manufacturer's instructions (Annexin-PI kit: ThermoFisher, V13242) and analyzed by flow cytometry.

Rhodamine assay: Cells were seeded at 300000 cells/well of 6 wells plate and treated with either TRAM-34 (100 nM) or control. After 24h of culture, cells were harvested, washed in PBS and incubated with rhodamine for $1 \mathrm{~h}(5 \mu \mathrm{M}$, ThermoFisher). Afterwards, cells were washed by PBS and analyzed by flow cytometry.

\section{Spheroids viability test}

Spheroids cell viability test was done according to manufacturer's conditions (Cultrex proliferation - cell viability 3510096K, R\&D Systems, Bio-Techne, Abingdon, UK). Cells were cultured in extracellular matrix supplemented with EGF in a round-shaped well bottom 96-well plate for $48 \mathrm{~h}$ then treated with TRAM-34 (100 nM) for $72 \mathrm{~h}$. To capture the entire spheroid, image fields (starting at the center of the well) were collected from each well using a x20 objective.

\section{MTT assay}

Cells were cultured for $24 \mathrm{~h}$ then treated with TRAM-34 (100nM). After 24h, MTT solution $(0.5 \mathrm{mg} / \mathrm{ml})$ was added to each well prior to incubation then HCT116 were incubated at $37^{\circ} \mathrm{C}$ for $45 \mathrm{~min}$ and $80 \mathrm{~min}$, respectively. Afterwards, supernatant was removed and dimethyl sulfoxyde (DMSO) was added to dissolve formazan crystals and absorbance was read at 570 nm using Mithras LB 940 Multimode Microplate Reader (Berthold, Bad Wildbad, Germany).

\section{XCELLigence migration test}

For Transwell migration studies, experiments were performed using xCELLigence RTCA DP system (ACEA Biosciences; Agilent, San Diego, CA, USA). Briefly, media in the bottom well contained Mc Coy'5A with 10\% FBS. After background determination, 40,000 HCT116 cells were added to the top well. Migration was monitored via real-time impedance measurements for $24 \mathrm{~h}$. Experiments were performed according to the manufacturer's instructions. 


\section{Store operated Ca2+ entry measurement by Fura-2 AM}

Cells were plated in 96 well plates at 20000 cells per well $24 \mathrm{~h}$ before the experiment. Adherent cells were loaded for 45 minutes at $37{ }^{\circ} \mathrm{C}$ with the ratiometric dye Fura2-AM $(5 \mu \mathrm{M})$ then washed by PBS solution supplemented with $\mathrm{Ca} 2+$. During the experiment, cells were incubated with Physiologic Saline Solution PSS Ca2+ free solution and treated by $2 \mu \mathrm{M}$ thapsigargin (TG, T7458, Life Technologies, ThermoFisher) to deplete intracellular store of Ca2+. Calcium entry was stimulated by injection of $2 \mathrm{mM}$ of $\mathrm{CaCl}_{2}$. Fluorescence emission was measured at $510 \mathrm{~nm}$ using the FlexStation-3 (Molecular Devices, San José, CA, USA) with excitation at 340 and $380 \mathrm{~nm}$. Maximum of fluorescence (peak of Ca2+ influx F340/F380) is measured and compared to normal condition. SK4 was inhibited by 100 nM TRAM-34 or $100 \mathrm{nM}$ charybdotoxin.

\section{Constitutive Ca2+ entry was measurement by Mn2+ quenching}

Cells were plated in 96 well plates at 20000 cells per well $24 \mathrm{~h}$ before the experiment. Adherent cells were loaded for 45 minutes at $37{ }^{\circ} \mathrm{C}$ with the ratiometric dye Fura2-AM $(5 \mu \mathrm{M})$ then washed by PBS solution supplemented with $\mathrm{Ca} 2+$. During the experiment, cells were incubated with PSS Ca2+ free solution and treated by $0.9 \mathrm{mM}$ of Manganese Mn2+ (manganese chloride, Sigma-Aldrich). Fluorescence emission was measured at $510 \mathrm{~nm}$ using the FlexStation-3 with excitation at $360 \mathrm{~nm}$. SK4 was inhibited by $100 \mathrm{nM}$ TRAM-34.

\section{Patch-clamp experiments}

Electrophysiological recordings were performed in the whole cell configuration of the patch clamp technique as already described [6]. Patch pipettes (2.0-4.0 M $\Omega$ ) were filled with a pipette solution contained (in mM): $\mathrm{KCl} 145, \mathrm{MgCl} 2$ 1, Mg-ATP 1, HEPES 10, $\mathrm{CaCl}_{2}$ 0.87, EGTA 10, adjusted to $\mathrm{pH} 7.2$ with $\mathrm{KOH}, \mathrm{pCa} 6$ (final $\mathrm{Ca} 2+$ concentration: $1 \mu \mathrm{M}$ ). Whole-cell macroscopic currents in HCT116 cells were measured using voltage clamp mode and using stepwise $10 \mathrm{mV}$ depolarizing pulses (350ms duration; $4 \mathrm{sec}$ intervals) from a constant holding potential of -40 $\mathrm{mV}$ and from potentials from $-100 \mathrm{mV}$ up to $+100 \mathrm{mV}$. Signals were filtered at $1 \mathrm{kHz}$ and digitized at $5 \mathrm{kHz}$. The steady state current elicited (to build IV relation) at chosen membrane potential was calculated as the average of the current recorded during the latest $50 \mathrm{~ms}$ of the pulse. Current amplitudes of SK4 channels were analyzed at $0 \mathrm{mV}$ to minimize chloride currents $\left(\mathrm{ECl}^{-}=0 \mathrm{mV}\right)$. Voltage clamp protocols were generated and the data captured with a computer using a Digidata 1200 interface, Axopatch 200B amplifier and pClamp9 software (Axon Instruments, Molecular Devices). The analysis was carried out using Clampfit 9 (Axon Instruments) and Origin 7.0 (Microcal Software). SK4 inhibition was done using Charybdotoxin $(100 \mathrm{nM})$. Current-clamp $(\mathrm{I}=0)$ experiments were performed using the whole- 
cell recording configuration of the patch-clamp technique. Current measurements were performed with $100 \mu \mathrm{M}$ niflumic acid (NFA) extracellularly to block chloride currents.

\section{Analysis of public datasets}

Transcriptomics: the publicly available CRC datasets from TCGA (https://portal.gdc.cancer.gov/) [12], GSE39582 [13] and GSE41258 [14] were downloaded and analyzed as described previously [7]. For the TCGA dataset, KRAS, BRAF and TP53 mutations, determined by next generation sequencing (NGS), were acquired from cbioportal using the gdsr package in R environment. Immunohistochemistry (IHC) staining for SK4 were obtained from The Human Protein Atlas database (http://www.proteinatlas.org) [15].

Proteomics: ninety-six CRC samples with paired normal tissues were evaluated by TMT10plex isobaric labeling quantification by the Pacific Northwest National Laboratory (PNNL) [16]. Log2-transformed relative protein abundance data were downloaded from the Clinical Proteomic Tumor Analysis Consortium (CPTAC) data portal.

\section{Intracellular ROS production}

ROS production was measured by 2',7'-Dichlorofluorescein diacetate (DCFDA) assay according to manufacturer's protocol (Molecular probes, ThermoFisher). Cells were seeded at $20.10^{3}$ cells/well of 96 well plates $24 \mathrm{~h}$ before the experiment. Cells were washed by PSS $2 \mathrm{mM}$ $\mathrm{Ca} 2+$ then treated with PSS $2 \mathrm{mM} \mathrm{Ca} 2+$ and $10 \mu \mathrm{M}$ DCFDA with or without TRAM-34 $100 \mathrm{nM}$. Fluorescence emission was measured at $520 \mathrm{~nm}$ using the FlexStation-3 with excitation at 500 $\mathrm{nm}$. Fluorescence rate was reported as relative fluorescence unit RFU normalized to time 0 .

\section{NanoLuc activity assay}

The HIF1A-NanoLuc and NFE2L2-NanoLuc protein-reporter HCT116 cell lines were purchased from Horizon Discovery (Cambridge, UK). Cells were seeded in 96 well plates at 30000 cells/well and incubated for $24 \mathrm{~h}$ in normoxia or hypoxia conditions $\left(1 \% \mathrm{O}_{2}\right)$ with or without TRAM-34 (100nM) treatment. Luciferase activity was measured using Nano-Glo® Reagent (Nano-Glo® Luciferase Assay, Promega) following the supplier's instruction. Luminescence intensity values were measured by FlexStation-3 (Molecular Devices, San José, CA, USA).

\section{Gene set enrichment analysis}

Gene set enrichment analysis (GSEA) was performed on the proteomics CRC dataset using GSEA software from the Broad Institute using default parameters [17]. Proteins were first 
ranked based on the statistic of their Pearson correlation with SK4. Pre-ranked GSEA was performed using the gene set of NRF2 putative targets downloaded from the molecular signature database.

\section{Statistical analysis}

Statistical analysis was performed using Graph-pad 6 Prism for in vitro studies and R-software for dataset analyses. Statistical tests (Student t-test, Wilcoxon or Mann-Whitney) and significancy are indicated in main text and/or figure legends. Data are expressed as mean $+/-$ SD or SEM.

\section{Results}

\section{Expression of SK4 channel in colorectal cancer}

We previously reported an increase in SK4 mRNA levels in CRC tumors compared to normal adjacent colorectal mucosa [7]. To investigate the expression of SK4 protein in CRC, we examined a proteomics dataset from (CPTAC) data portal of paired normal and CRC tissues from 96 patients. Results showed a significant increase in SK4 protein levels compared to normal tissues (Figure 1 A). Next, we examined the expression of SK4 in histological images of normal and tumor colorectal samples downloaded from the human protein atlas (http://www.proteinatlas.org/), and observed an increase in the immunohistochemical staining of SK4 in CRC compared to normal tissues (Figure 1 B) confirming our previous findings. We also examined two transcriptomic CRC datasets (TCGA and GSE39582) to analyze the correlation of KCNN4 expression with the mutational status of TP53, BRAF and KRAS, which occur frequently in CRC [18]. Data showed that within CRC tumors, KCNN4 expression was increased in KRAS-mutated samples compared to wild type in both datasets (TCGA: Fold change: 0.55, P value <0.001, GSE39582: Fold change 0.37, P value <0.001) (Figure 1 E), but no correlation was found for TP53 or BRAF mutations (Figure $1 \mathbf{C}$ and D). Next, we investigated the transcriptional profile of $K C N N 4$ through the development of CRC using the GSE41258 dataset. As expected, KCNN4 expression is low in the normal colon, and it is even significantly lower in normal tissues from the lung and the liver, the metastases destinations for CRC. Interestingly, we found that KCNN4 levels are increased throughout CRC development from adenoma stage to metastasis and remains elevated in liver and lung metastasis, compared to normal tissues (Figure 1F). Together, these data indicate that SK4 is often overexpressed in CRC, more particularly those harboring KRAS mutations. 


\section{SK4 expression and effect of charybdotoxin on modulation of membrane potential in CRC cell lines}

To investigate the role of SK4 in CRC, we studied its expression in colorectal cancer cell lines with or without KRAS mutation. Interestingly, HCT116 and SW480 cells, both harboring KRAS mutation, showed a higher expression level of $K C N N 4(\triangle \mathrm{Ct}=1.26$ and 0.84 respectively) compared to the KRAS non-mutated SW48 and HT29 cells $(\Delta \mathrm{Ct}=5.14$ and 5.19 respectively) (Figure 2 A). To further investigate the association between KRAS mutation and KCNN4 expression, HCT116 cells were transfected with two distinct siRNA against KRAS. Results showed that $K R A S$-silencing decreased the expression of $K C N N 4$ (Figure 2 B), indicating that $K R A S$ mutation could induce the expression of KCNN4.

To study the activity of SK4 channel of HCT116 cells, we tested the effect of charybdotoxin (a well-known SK4 channel blocker) on currents using the whole-cell configuration of patchclamp technique. As expected, patch-clamp experiments revealed an inward rectification of the current-density relationship that is typical for SK4 channel activity, which was reduced by charybdotoxin (current density at $0 \mathrm{mV} 5.85 \pm 1.62 \mathrm{pA} / \mathrm{pF}$ to $1.47 \pm 0.26 \mathrm{pA} / \mathrm{pF}$ ) (Figure 2 C). Next, we recorded the effect of charybdotoxin on the membrane potential of HCT116 cells by patch clamp, using current clamp method. Knowing that membrane potential is mainly regulated by $\mathrm{Cl}^{-}$and $\mathrm{K}^{+}$channels, we used NFA in control condition to eliminate the physiological effects of chloric channels in regulating membrane potential [19]. In presence of NFA in the bath solution the resting membrane potential is $-50 \mathrm{mV}$. Application of charybdotoxin at $100 \mathrm{nM}$ depolarized plasma membrane from $-49.58 \pm 5.73 \mathrm{mV}$ to $-21.1 \pm 4.86$ $\mathrm{mV}(\mathrm{n}=7 ; \mathrm{p}<0.05$, Paired t-test) (Figure 2 D). To demonstrate a possible link between the activity of SK4 and Ca2+ influx by modification of the membrane potential, we depolarized cells with $40 \mathrm{mM} \mathrm{KCl}$ (a condition for which we have already demonstrated that plasma membrane was more positive, reducing the driving force for $\mathrm{Ca} 2+$ entry [20]). As expected, the decrease of driving force for $\mathrm{Ca} 2+$ entry decreased SOCE Ca2+ entry in HCT116 cells without additional effect with TRAM-34 (Supplementary Figure S1). At the opposite the variation of $\mathrm{KCl}$ had no effect on $\mathrm{Ca} 2+$ entry in HT29 (without KRAS mutation and without KCNN4 expression) (Supplementary Figure S1).

Taken together our experiments suggest a pivotal role of SK4 to control the membrane potential and $\mathrm{Ca} 2+$ influx in KRAS-mutated cells. These results suggest that SK4 channels hyperpolarize the plasma membrane of HCT116 cells. 


\section{SK4 inhibition reduces Store Operated $\mathrm{Ca} 2+$ Entry (SOCE) and constitutive calcium entry (CCE) in HCT116}

The association between $\mathrm{Ca} 2+$ and potassium channels is essential for $\mathrm{Ca} 2+$ homeostasis and tumor progression [4]. The activation of $\mathrm{KCa}$ channels increases $\mathrm{Ca} 2+$ driving force of SOCE and CCE by hyperpolarization of the plasma membrane. At the opposite, the blockage of SK4 can lead to a membrane depolarization and to a decrease of the driving force for $\mathrm{Ca} 2+$. In colon cancer cells, we recently reported that SK3 channel, along with TRPC1 and Orai1 Ca2+ channels, promote SOCE-dependent migration [6]. Moreover, we found that SK3 association with Orai1 regulate $\mathrm{Ca} 2+$ homeostasis [5].

Therefore, we tested the impact of TRAM-34, a highly specific inhibitor of SK4 [21], and charybdotoxin on SOCE in HCT116 cells using Fura-2AM. Both inhibitors significantly reduced $\mathrm{Ca} 2+$ entry after SOCE activation by TG, compared to control cells (Figure 3 A, Supplementary Figure S2 A). These effects were also observed on the metastatic cell line Lovo (Supplementary Figure S3 A, B). Moreover, targeting KCNN4 in HCT116 cells by siRNA also reduced SOCE (Figure 3 B). It is noteworthy that the inhibition of SK4 by TRAM34 in HT29 cells did not affect SOCE (Supplementary Figure S2 B) indicating that the effect of TRAM-34 effect on HCT116 cells is specific. These data indicate that SK4 channel could modulate cell migration through SOCE regulation.

Unlike SOCE, CCE mechanisms and regulating players are less studied. Recently, it was shown that in metastatic CRC cells, CCE is regulated by STIM1, Orai1 and Orai3 [22]. This constitutive $\mathrm{Ca} 2+$ current was measured by $\mathrm{Mn} 2+$ quenching technique [22]. In order to determine the key players of CCE in HCT116 cells, we tested the effects of different pharmacological inhibitors of Orai1 and TRP channels on the Mn2+ quenching rate of Fura2AM fluorescence at $360 \mathrm{~nm}$. We tested synta66 $(10 \mu \mathrm{M})$, an inhibitor of SOCE, and SKF96365 $(40 \mu \mathrm{M})$ and 2-APB $(100 \mu \mathrm{M})$ two inhibitors of both Orai1 and TRP families. We found that Synta66 only partially reduced Mn2+ quenching rate compared to 2-APB and SKF96365 compounds, which both reduced almost half of the Mn2+ quenching rate (Figure $3 \mathbf{C}$ ). These pharmacological findings were also validated using siRNAs againstTRPC1 and Orail (Supplementary Figure S2 C). This indicates that Orai1 and TRPC1 channels participate to CCE in HCT116 cells.

Besides, SK3 channel modulates the CCE mediated by Orai1 in MDA-MB-435 cells [5, 23]. Moreover, in breast cancer cells MCF-7, it was showed that SK4 and TRPC1 complexes 
regulate CCE [24]. Based on those results, we hypothesized that SK4 could modulate CCE in HCT116 cells. Therefore, we tested TRAM-34 and charybdotoxin on CCE in HCT116 cells and found that both reduced the Mn2+ quenching rate, suggesting that SK4 plays a role in the modulation of CCE (Figure 3 D, Supplementary Figure S4 A). The same pattern was observed with Lovo cells treated with charybdotoxin or TRAM-34 (Supplementary Figure S3 C and D). Moreover, targeting KCNN4 in HCT116 cells by siRNA also reduced the Mn2+ quenching rate (Supplementary Figure S4 B).

\section{Effect of TRAM-34 on cell proliferation, invasion and migration}

Our next aim was to study the implication of SK4 channel in cell viability and cell proliferation. Results showed that TRAM-34 did not affect the proliferation in 2D and 3D culture (Figure 4 A and 4 B), and did not alter the proportions of cell cycle phases (Figure 4 C). Likewise, knock down of KCNN4 by siRNAs (Figure 4D) has no effect on cell cycle. Moreover, TRAM-34, even at higher dose, did not induce apoptosis in HCT116 cells (Supplementary Figure S5).

Store operated $\mathrm{Ca} 2+$ entry "SOCE" has been recently reported to regulate cell migration in CRC cells [6] thus, we investigated the role of SK4 in the migration and invasion of HCT116 cells. We found that SK4 inhibition by TRAM-34 significantly reduced cell invasion at $24 \mathrm{~h}$, compared to control ( $\mathrm{P}<0.01$, Mann Whitney test) (Figure $4 \mathbf{E}$ ). We also found that TRAM-34 $(100 \mathrm{nM})$ significantly reduced the number of migrated cells at $24 \mathrm{~h}$, compared to control ( $\mathrm{P}<0.01$, Mann Whitney test) (Figure 4 F). Transwell assays using the xCELLigence RTCA system were realized to test the effect of siSK4 on the regulation of cellular migration. The results showed that the inhibiting SK4 by TRAM-34 or silencing its expression by siRNA reduced cell-index (Figure $4 \mathbf{G}$ ), thus confirming the active role of SK4 channel on cell migration and cell invasion. Altogether, these data suggest an active and a pivotal role of SK4 channel in the migration/invasion of colon cancer cells may be linked to metastasis development.

\section{SK4 channel enhances ROS production in CRC cells}

Knowing that ROS are intimately linked with cancer cell migration [11] and that calcium signaling, ROS and cancer hallmarks are highly interconnected [25], we next investigated the role of SK4 channel in ROS homeostasis. For this purpose, we studied the effect of SK4 inhibition on cytoplasmic ROS production. SK4 inhibition by TRAM-34 reduced ROS 
generation in HCT116 (Figure 5 A, B). To further investigate the association between SK4 and oxidative stress, we studied consequences of SK4 inhibition on the stabilization of hypoxia inducible factor alpha protein, using Nanoluc inducible-HIF1 $\alpha$ HCT116 cells. In normoxia, HIF1 $\alpha$ is targeted for degradation by by prolyl-hydroxylase (PHD) activity, but following acute hypoxia, ROS generated by oxidative stress inactivate PHD and result in the stabilization of HIF1 $\alpha$ protein. Our data showed that HIF1 $\alpha$ expression, as measured by Nanoluc activity, was significantly increased under hypoxia as expected, and was strikingly reduced following SK4 inhibition (Figure 5 C). Moreover, the activation of NRF2 and the induction of its target genes are well established markers of the response to oxidative stress in cancer [26]. Interestingly, Gene set enrichment analysis (GSEA) on a proteomic analysis of CRC primary tissues revealed a significant correlation between SK4 protein expression and targets of NRF2 (Figure 5 D). To confirm this result, we studied the effect of SK4 inhibition on NFR2 expression using NEFLE2Nanoluc assay. Interestingly, NEFLE2-dependent nanoluc activity was higher in cells cultured under hypoxia compared to normoxia and SK4 inhibition reduced this activity in both conditions (Figure 5 E).

Together, those results suggest that SK4 channel may contributes to ROS production in CRC cells and could regulate NRF2 and HIF1a activity.

\section{Discussion}

In the present study, we showed that SK4 is highly expressed in CRC cells and its expression is increased in tumors with KRAS mutation. SK4 channel controls membrane potential and contributes to the regulation of cytosolic $\mathrm{Ca} 2+$ concentration by modulation of, both, SOCE and CCE. Moreover, SK4 channel is an important contributor to CRC cells migration and invasion but does not modulate cell survival and proliferation.

In the last few years, many studies have reported that SK4 is highly expressed in tumor tissues compared to normal ones, i.e. lung cancer [27], breast cancer [28], glioblastoma [29], renal cancer [30] and cholangiocarcinoma [31]. We recently detected an increase in KCNN4 levels in CRC tumor tissues in comparison to adjacent normal colorectal mucosa [7]. Here, we showed using public proteomics data and immunohistochemical staining images that SK4 expression is increased in CRC. The increase of SK4 in tumors uncovers its possible role in carcinogenesis and explains the interest in studying the functionality and the biological processes linked to this channel. 
Epigenetic dysregulation of SK4 promotes poor prognosis in lung cancer [27]. SK4 was found to be highly expressed in $32 \%$ of glioma patients and was correlated with shortened survival [29]. SK4 mRNA expression is correlated with poor prognosis in breast cancer [24].

KRAS mutation is the most common mutation in CRC cancer and it is found in $45 \%$ of CRC. The administration of EGFR antibodies along with chemotherapy improved clinical outcome in metastatic CRC (mCRC) [32]. However, mCRC patients harboring KRAS mutation are resistant to anti-EGFR therapy as a result of constitutive activation of the RAS-RAF-MEKERK pathway [33].It was shown recently that KRAS mutation is correlated with shorter OS in patients with microsatellite-stability MSS [34]. Interestingly, the expression of SK4 is increased upon activation of RAS/ERK signaling pathway in fibroblasts [35]. This is in accordance with our results that show an increase of KCNN4 in tumors with KRAS mutations. Moreover, our results show that the expression level of $K C N N 4$ is higher in KRAS-mutated CRC cell lines compared to those harboring wild-type $K R A S$.

SOCE effectors in normal colon cells are STIM1, STIM2 and Orai1 [36]. However, SOCE is mediated by STIM1, Orai1, TRPC1 and SK3 channel complexes in cancerous colonic cells [37], indicating SOCE remodeling in CRC. Indeed, the complex SK3/TRPC1/ORAI1 is implicated in CRC cell migration [6], and the inhibition of SOCE by salicylate was proposed as a possible mechanism for cancer chemoprevention by non-steroidal anti-inflammatory drugs [38]. Moccia and colleagues showed that STIM1 and ORAI3 are upregulated in metastatic CRC cell lines, but, nonetheless they detected a slight decrease in SOCE compared to cell lines derived from primary $\mathrm{CRC}$ with a much higher decrease in constitutive $\mathrm{Ca} 2+$ entry [22]. Another study by Pierro et al showed that the KRAS ${ }^{\mathrm{G} 13 \mathrm{D}}$ mutation is associated with STIM1 decrease and STIM2 increase (STIM remodeling), in addition to reduced ICRAC current [39], but the effect on SOCE was not clearly demonstrated. Besides, our previous work validates the importance of SOCE and STIM1 in HCT116 cell migration [6]. However, possible discrepancies may exist between cell lines and primary tumors, and further experiments are needed to validate these effects in primary CRC.

Our results demonstrate that in KRAS-mutated CRC cells, HCT116 and LoVo, the inhibition of SK4 channels reduces SOCE. This suggests that SK4 channels participate to SOCE in KRASmutated CRC as a novel mechanism of SOCE remodeling. Moreover, we proved that SK4 participate to constitutive $\mathrm{Ca} 2+$ influx. Patch clamp data showed a role for SK4 channel in regulating the membrane potential of $K R A S$-mutated colorectal cancer cells. In summary, the 
presence of SK4 in $K R A S$-mutated CRC results in plasma membrane hyperpolarization and increases the $\mathrm{Ca} 2+$ driving force in order to potentiate the different $\mathrm{Ca} 2+$ entry pathways. We also demonstrated that Orai1 contributes to this influx in HCT116 cells. Therefore, this suggests the possibility of a physical or functional interaction between SK4 with other Ca2+ partners (Orai1 and TRPC1) regulating constitutive Ca2+ entry in HCT116 cells.

Prevarskaya and colleagues found that SK4 regulate prostate cancer cell proliferation through a tight control of Ca2+ entry [40]. Moreover, Faouzi et al showed that SK4 modulates breast cancer cell proliferation [24]. Nevertheless, our results showed that cell cycle and cell division rate did not change when treating HCT116 cells with TRAM-34 at a concentration that is sufficient to inhibit SK4 channel. This is in line with our previous finding showing that neither the ablation of SOCE effectors nor that of SK3 affected HCT116 cell proliferation [6].

The implication of SK4 channel in cell migration and invasion indicate a possible role in tumor cells invasiveness and metastasis. Following TRAM-34 treatment, mice bearing glioblastoma showed lower tumor infiltration into the brain parenchyma, indicating a role of SK4 in glioblastoma invasiveness [41]. Likewise, in vitro and in vivo experiments revealed that SK4 confers an invasive phenotype in glioblastoma [29]. Consistent with findings in other cancers, we showed that the inhibition of SK4 channel reduced HCT116 cell migration. SK4-dependent migration of CRC cells could be mediated by either SOCE or CCE, and more studies are needed for more precise clarification of the implicated $\mathrm{Ca} 2+$ entry mode. Similarly to our previous findings on SK3 [6], SK4 channel could contribute to the mechanics of migration and possibly invasion, via calpain ( $\mathrm{Ca} 2+-$-sensitive protease) activation of matrix metalloproteinases. We also believe that the role of integrins should be studied since our migration and invasion experiments have been carried out on support matrices: fibronectin for migration, and matrigel for invasion. A link between SK4, $\beta 1$-integrin and migration has been shown in cell repair processes. It is therefore important to explore in the future the link between SK4 channel and integrins in metastatic development [42].

It is established that the increase of ROS and the modification of mitochondrial $\mathrm{Ca} 2+$ buffering can both affect the activity of Ca2+ channels in the plasma membrane [43, 44]. SK4 was found in the inner mitochondrial membrane of CRC cells and it was proposed that $\mathrm{Ca} 2+$ entry could be modulated by the mitochondrial SK4 [45]. Therefore, we assumed that SK4 blockade should increase ROS as well as mitochondrial Ca2+ concentration. However, since SK4 inhibition did 
not affect mitochondrial Ca2+ (Supplementary Figure S6), we suggest that plasma membrane SK4 channels are the ones modulating $\mathrm{Ca} 2+$ entry.

Oxidative stress is implicated in the regulation of biological processes leading to malignancy. The cross-talk between ROS and Ca2+ in cancer cells was described at many levels [46]. Our results show that SK4 inhibition reduces ROS and HIF1 $\alpha$ stability as well as NRF2 expression. These results strengthen the links between SK4 and KRAS mutation. The positive feedback between oncogenic KRAS and HIF-1 $\alpha$, that confers drug resistance in colorectal cancer, has already been described [47]. In pancreatic ductal adenocarcinoma, oncogenic KRAS activates expression of a series of anti-oxidant genes, via NRF2, and also mediates an unusual metabolic pathway of glutamine to generate NADPH [48]. Oncogenic mutation of KRAS enhanced resistance of cells to cisplatin in an NRF2-dependent manner. The authors demonstrated that KRAS was able to transcriptionally activate NRF2 through KRAS-ERK pathway [49]. More recently, a study showed that KRAS suppresses P53 by activating the NRF2-regulated antioxidant system [50]. Likewise, the expression and function of SK4 is associated with the regulation of NRF2, HIF-1 $\alpha$ and ROS production.

The decrease in HIF1 $\alpha$ stability under hypoxia after TRAM-34 treatment suggests that SK4 inhibition also reduces intracytoplasmic ROS in hypoxic environment. ROS major intracellular sources are the mitochondria and NADPH oxidases. The fact that TRAM-34 did not affect mitochondrial $\mathrm{Ca} 2+$ suggests no effect on mitochondrial ROS generation. The partial inhibition of SOCE and SICE by TRAM-34 reduces cytoplasmic $\mathrm{Ca} 2+$ levels needed for the activation of NADPH-oxidase and thereby could be reducing their activity.

Noteworthy, Senicapoc, a drug previously developed to reduce sickle cell anemia endpoints, has recently been repurposed to block SK4 in hereditary xerocytosis [51]. In a near future, it could be relevant to test this drug or its analogues in regard of our present findings.

\section{Conclusion}

In summary, this study shows that SK4 expression is increased in CRC and regulates plasma membrane voltage and $\mathrm{Ca} 2+$ entry in CRC cells. SK4 channel is also implicated in the migration and invasion of HCT116 cells potentially by shutting down Ca2+ and ROS signaling. Taken together, our data suggest SK4 as an oncochannel which could be a highly promising therapeutic target to slowdown metastases in KRAS-mutated CRC patients. 


\section{Acknowledgments}

We thank Pr Christophe Vandier for critical review of the manuscript. This project was partly supported by grants on behalf of the following french department committees of Ligue Contre le Cancer Grand-Ouest: 16 (Charente), 37 (Indre-et-Loire), 49 (Maine-et-Loire), 72 (Sarthe) and 85 (Vendée). Maxime Guéguinou is a recipient of a 3-years postdoctoral grant from Région Centre - Val de Loire. Sajida Ibrahim was funded by ARFMAD (Association Recherche et Formation dans les Maladies de l'Appareil Digestif). Justine Chaigne was funded by Ligue Contre le Cancer. Inserm UMR 1069 is leader of Cancéropole Grand-Ouest 3MC network (Marine Molecules, Metabolism and Cancer), member of Région Centre - Val de Loire thematic research consortium RTR MOTIVHEALTH (Molecular and Technological Innovation for Health) and member of CNRS research group APPICOM (Integrative Approach for a multiscale functional analysis of membrane proteins).

We acknowledge Inserm, Université de Tours and Région Centre-Val de Loire for their financial supports.

\section{Data Availability}

The data that support the findings of this study are available from the corresponding author upon reasonable request.

\section{Conflicts of interest}

The authors declare no potential conflicts of interest.

\section{Bibliography}

[1] N. Prevarskaya, H. Ouadid-Ahidouch, R. Skryma, Y. Shuba, Remodelling of Ca2+ transport in cancer: how it contributes to cancer hallmarks?, Philos Trans R Soc Lond B Biol Sci, 369 (2014) 20130097.

[2] F. Gackiere, M. Warnier, M. Katsogiannou, S. Derouiche, P. Delcourt, E. Dewailly, C. Slomianny, S. Humez, N. Prevarskaya, M. Roudbaraki, P. Mariot, Functional coupling between large-conductance potassium channels and Cav3.2 voltage-dependent calcium channels participates in prostate cancer cell growth, Biol Open, 2 (2013) 941-951.

[3] M. Potier, V. Joulin, S. Roger, P. Besson, M.L. Jourdan, J.Y. Leguennec, P. Bougnoux, C. Vandier, Identification of SK3 channel as a new mediator of breast cancer cell migration, Mol Cancer Ther, 5 (2006) 2946-2953.

[4] M. Potier-Cartereau, W. Raoul, G. Weber, K. Maheo, R. Rapetti-Mauss, M. Gueguinou, P. Buscaglia, C. Goupille, N. Le Goux, S. Abdoul-Azize, T. Lecomte, G. Fromont, A. Chantome, O. Mignen, O. Soriani, C. Vandier, Potassium and Calcium Channel Complexes as Novel Targets for Cancer Research, Rev Physiol Biochem Pharmacol, (2020). 
[5] M. Gueguinou, D. Crottes, A. Chantome, R. Rapetti-Mauss, M. Potier-Cartereau, L. Clarysse, A. Girault, Y. Fourbon, P. Jezequel, C. Guerin-Charbonnel, G. Fromont, P. Martin, B. Pellissier, R. Schiappa, E. Chamorey, O. Mignen, A. Uguen, F. Borgese, C. Vandier, O. Soriani, The SigmaR1 chaperone drives breast and colorectal cancer cell migration by tuning SK3-dependent $\mathrm{Ca}(2+)$ homeostasis, Oncogene, 36 (2017) 3640-3647.

[6] M. Gueguinou, T. Harnois, D. Crottes, A. Uguen, N. Deliot, A. Gambade, A. Chantome, J.P. Haelters, P.A. Jaffres, M.L. Jourdan, G. Weber, O. Soriani, P. Bougnoux, O. Mignen, N. Bourmeyster, B. Constantin, T. Lecomte, C. Vandier, M. Potier-Cartereau, SK3/TRPC1/Orai1 complex regulates SOCEdependent colon cancer cell migration: a novel opportunity to modulate anti-EGFR mAb action by the alkyl-lipid Ohmline, Oncotarget, 7 (2016) 36168-36184.

[7] S. Ibrahim, H. Dakik, C. Vandier, R. Chautard, G. Paintaud, F. Mazurier, T. Lecomte, M. Gueguinou, W. Raoul, Expression Profiling of Calcium Channels and Calcium-Activated Potassium Channels in Colorectal Cancer, Cancers (Basel), 11 (2019).

[8] J. Maylie, C.T. Bond, P.S. Herson, W.S. Lee, J.P. Adelman, Small conductance Ca2+-activated K+ channels and calmodulin, J Physiol, 554 (2004) 255-261.

[9] H. Jager, T. Dreker, A. Buck, K. Giehl, T. Gress, S. Grissmer, Blockage of intermediate-conductance

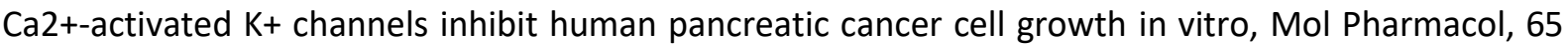
(2004) 630-638.

[10] B. Stegen, L. Klumpp, M. Misovic, L. Edalat, M. Eckert, D. Klumpp, P. Ruth, S.M. Huber, K(+) channel signaling in irradiated tumor cells, Eur Biophys J, 45 (2016) 585-598.

[11] W.S. Wu, J.R. Wu, C.T. Hu, Signal cross talks for sustained MAPK activation and cell migration: the potential role of reactive oxygen species, Cancer Metastasis Rev, 27 (2008) 303-314.

[12] R.L. Grossman, A.P. Heath, V. Ferretti, H.E. Varmus, D.R. Lowy, W.A. Kibbe, L.M. Staudt, Toward a Shared Vision for Cancer Genomic Data, N Engl J Med, 375 (2016) 1109-1112.

[13] L. Marisa, A. de Reynies, A. Duval, J. Selves, M.P. Gaub, L. Vescovo, M.C. Etienne-Grimaldi, R. Schiappa, D. Guenot, M. Ayadi, S. Kirzin, M. Chazal, J.F. Flejou, D. Benchimol, A. Berger, A. Lagarde, E. Pencreach, F. Piard, D. Elias, Y. Parc, S. Olschwang, G. Milano, P. Laurent-Puig, V. Boige, Gene expression classification of colon cancer into molecular subtypes: characterization, validation, and prognostic value, PLoS Med, 10 (2013) e1001453.

[14] M. Sheffer, M.D. Bacolod, O. Zuk, S.F. Giardina, H. Pincas, F. Barany, P.B. Paty, W.L. Gerald, D.A. Notterman, E. Domany, Association of survival and disease progression with chromosomal instability: a genomic exploration of colorectal cancer, Proc Natl Acad Sci U S A, 106 (2009) 7131-7136.

[15] M. Uhlen, L. Fagerberg, B.M. Hallstrom, C. Lindskog, P. Oksvold, A. Mardinoglu, A. Sivertsson, C. Kampf, E. Sjostedt, A. Asplund, I. Olsson, K. Edlund, E. Lundberg, S. Navani, C.A. Szigyarto, J. Odeberg, D. Djureinovic, J.O. Takanen, S. Hober, T. Alm, P.H. Edqvist, H. Berling, H. Tegel, J. Mulder, J. Rockberg, P. Nilsson, J.M. Schwenk, M. Hamsten, K. von Feilitzen, M. Forsberg, L. Persson, F. Johansson, M. Zwahlen, G. von Heijne, J. Nielsen, F. Ponten, Proteomics. Tissue-based map of the human proteome, Science, 347 (2015) 1260419.

[16] S. Vasaikar, C. Huang, X. Wang, V.A. Petyuk, S.R. Savage, B. Wen, Y. Dou, Y. Zhang, Z. Shi, O.A. Arshad, M.A. Gritsenko, L.J. Zimmerman, J.E. McDermott, T.R. Clauss, R.J. Moore, R. Zhao, M.E. Monroe, Y.T. Wang, M.C. Chambers, R.J.C. Slebos, K.S. Lau, Q. Mo, L. Ding, M. Ellis, M. Thiagarajan, C.R. Kinsinger, H. Rodriguez, R.D. Smith, K.D. Rodland, D.C. Liebler, T. Liu, B. Zhang, C. Clinical Proteomic Tumor Analysis, Proteogenomic Analysis of Human Colon Cancer Reveals New Therapeutic Opportunities, Cell, 177 (2019) 1035-1049 e1019.

[17] A. Subramanian, P. Tamayo, V.K. Mootha, S. Mukherjee, B.L. Ebert, M.A. Gillette, A. Paulovich, S.L. Pomeroy, T.R. Golub, E.S. Lander, J.P. Mesirov, Gene set enrichment analysis: a knowledge-based approach for interpreting genome-wide expression profiles, Proc Natl Acad Sci U S A, 102 (2005) 1554515550.

[18] T. Armaghany, J.D. Wilson, Q. Chu, G. Mills, Genetic alterations in colorectal cancer, Gastrointest Cancer Res, 5 (2012) 19-27.

[19] M.M. White, M. Aylwin, Niflumic and flufenamic acids are potent reversible blockers of Ca2(+)activated Cl- channels in Xenopus oocytes, Mol Pharmacol, 37 (1990) 720-724. 
[20] A. Chantome, A. Girault, M. Potier, C. Collin, P. Vaudin, J.C. Pages, C. Vandier, V. Joulin, KCa2.3 channel-dependent hyperpolarization increases melanoma cell motility, Exp Cell Res, 315 (2009) 36203630.

[21] H. Wulff, M.J. Miller, W. Hansel, S. Grissmer, M.D. Cahalan, K.G. Chandy, Design of a potent and selective inhibitor of the intermediate-conductance Ca2+-activated $\mathrm{K}+$ channel, IKCa1: a potential immunosuppressant, Proc Natl Acad Sci U S A, 97 (2000) 8151-8156.

[22] E. Zuccolo, U. Laforenza, F. Ferulli, G. Pellavio, G. Scarpellino, M. Tanzi, I. Turin, P. Faris, A. Lucariello, M. Maestri, D.A. Kheder, G. Guerra, P. Pedrazzoli, D. Montagna, F. Moccia, Stim and Orai mediate constitutive $\mathrm{Ca}(2+)$ entry and control endoplasmic reticulum $\mathrm{Ca}(2+)$ refilling in primary cultures of colorectal carcinoma cells, Oncotarget, 9 (2018) 31098-31119.

[23] A. Chantome, M. Potier-Cartereau, L. Clarysse, G. Fromont, S. Marionneau-Lambot, M. Gueguinou, J.C. Pages, C. Collin, T. Oullier, A. Girault, F. Arbion, J.P. Haelters, P.A. Jaffres, M. Pinault, P. Besson, V. Joulin, P. Bougnoux, C. Vandier, Pivotal role of the lipid Raft SK3-Orai1 complex in human cancer cell migration and bone metastases, Cancer Res, 73 (2013) 4852-4861.

[24] M. Faouzi, F. Hague, D. Geerts, A.S. Ay, M. Potier-Cartereau, A. Ahidouch, H. Ouadid-Ahidouch, Functional cooperation between KCa3.1 and TRPC1 channels in human breast cancer: Role in cell proliferation and patient prognosis, Oncotarget, 7 (2016) 36419-36435.

[25] J. Frisch, A. Angenendt, M. Hoth, L. Prates Roma, A. Lis, STIM-Orai Channels and Reactive Oxygen Species in the Tumor Microenvironment, Cancers (Basel), 11 (2019).

[26] J.D. Hayes, A.T. Dinkova-Kostova, K.D. Tew, Oxidative Stress in Cancer, Cancer Cell, 38 (2020) 167197.

[27] E. Bulk, A.S. Ay, M. Hammadi, H. Ouadid-Ahidouch, S. Schelhaas, A. Hascher, C. Rohde, N.H. Thoennissen, R. Wiewrodt, E. Schmidt, A. Marra, L. Hillejan, A.H. Jacobs, H.U. Klein, M. Dugas, W.E. Berdel, C. Muller-Tidow, A. Schwab, Epigenetic dysregulation of KCa 3.1 channels induces poor prognosis in lung cancer, Int J Cancer, 137 (2015) 1306-1317.

[28] N. Haren, H. Khorsi, M. Faouzi, A. Ahidouch, H. Sevestre, H. Ouadid-Ahidouch, Intermediate conductance $\mathrm{Ca} 2+$ activated $\mathrm{K}+$ channels are expressed and functional in breast adenocarcinomas: correlation with tumour grade and metastasis status, Histol Histopathol, 25 (2010) 1247-1255.

[29] K.L. Turner, A. Honasoge, S.M. Robert, M.M. McFerrin, H. Sontheimer, A proinvasive role for the $\mathrm{Ca}(2+)$-activated $\mathrm{K}(+)$ channel KCa3.1 in malignant glioma, Glia, 62 (2014) 971-981.

[30] M. Rabjerg, A. Olivan-Viguera, L.K. Hansen, L. Jensen, L. Sevelsted-Moller, S. Walter, B.L. Jensen, N. Marcussen, R. Kohler, High expression of KCa3.1 in patients with clear cell renal carcinoma predicts high metastatic risk and poor survival, PLoS One, 10 (2015) e0122992.

[31] P. Song, Y. Du, W. Song, H. Chen, Z. Xuan, L. Zhao, J. Chen, J. Chen, D. Guo, C. Jin, Y. Zhao, B. Tuo, S. Zheng, KCa3.1 as an Effective Target for Inhibition of Growth and Progression of Intrahepatic Cholangiocarcinoma, J Cancer, 8 (2017) 1568-1578.

[32] J.Y. Douillard, S. Siena, J. Cassidy, J. Tabernero, R. Burkes, M. Barugel, Y. Humblet, G. Bodoky, D. Cunningham, J. Jassem, F. Rivera, I. Kocakova, P. Ruff, M. Blasinska-Morawiec, M. Smakal, J.L. Canon, M. Rother, K.S. Oliner, M. Wolf, J. Gansert, Randomized, phase III trial of panitumumab with infusional fluorouracil, leucovorin, and oxaliplatin (FOLFOX4) versus FOLFOX4 alone as first-line treatment in patients with previously untreated metastatic colorectal cancer: the PRIME study, J Clin Oncol, 28 (2010) 4697-4705.

[33] A. Lievre, J.B. Bachet, D. Le Corre, V. Boige, B. Landi, J.F. Emile, J.F. Cote, G. Tomasic, C. Penna, M. Ducreux, P. Rougier, F. Penault-Llorca, P. Laurent-Puig, KRAS mutation status is predictive of response to cetuximab therapy in colorectal cancer, Cancer Res, 66 (2006) 3992-3995.

[34] J. Taieb, K. Le Malicot, Q. Shi, F. Penault-Llorca, O. Bouche, J. Tabernero, E. Mini, R.M. Goldberg, G. Folprecht, J. Luc Van Laethem, D.J. Sargent, S.R. Alberts, J.F. Emile, P. Laurent Puig, F.A. Sinicrope, Prognostic Value of BRAF and KRAS Mutations in MSI and MSS Stage III Colon Cancer, J Natl Cancer Inst, 109 (2017).

[35] T.L. Pena, S.H. Chen, S.F. Konieczny, S.G. Rane, Ras/MEK/ERK Up-regulation of the fibroblast KCa channel FIK is a common mechanism for basic fibroblast growth factor and transforming growth factorbeta suppression of myogenesis, J Biol Chem, 275 (2000) 13677-13682. 
[36] D. Sobradillo, M. Hernandez-Morales, D. Ubierna, M.P. Moyer, L. Nunez, C. Villalobos, A reciprocal shift in transient receptor potential channel 1 (TRPC1) and stromal interaction molecule 2 (STIM2) contributes to $\mathrm{Ca} 2+$ remodeling and cancer hallmarks in colorectal carcinoma cells, J Biol Chem, 289 (2014) 28765-28782.

[37] C. Villalobos, D. Sobradillo, M. Hernandez-Morales, L. Nunez, Calcium remodeling in colorectal cancer, Biochim Biophys Acta Mol Cell Res, 1864 (2017) 843-849.

[38] M. Hernandez-Morales, D. Sobradillo, R.A. Valero, E. Munoz, D. Ubierna, M.P. Moyer, L. Nunez, C. Villalobos, Mitochondria sustain store-operated currents in colon cancer cells but not in normal colonic cells: reversal by non-steroidal anti-inflammatory drugs, Oncotarget, 8 (2017) 55332-55352.

[39] C. Pierro, X. Zhang, C. Kankeu, M. Trebak, M.D. Bootman, H.L. Roderick, Oncogenic KRAS suppresses store-operated $\mathrm{Ca}(2+)$ entry and ICRAC through ERK pathway-dependent remodelling of STIM expression in colorectal cancer cell lines, Cell Calcium, 72 (2018) 70-80.

[40] H. Lallet-Daher, M. Roudbaraki, A. Bavencoffe, P. Mariot, F. Gackiere, G. Bidaux, R. Urbain, P. Gosset, P. Delcourt, L. Fleurisse, C. Slomianny, E. Dewailly, B. Mauroy, J.L. Bonnal, R. Skryma, N. Prevarskaya, Intermediate-conductance $\mathrm{Ca} 2+$-activated $\mathrm{K}+$ channels (IKCa1) regulate human prostate cancer cell proliferation through a close control of calcium entry, Oncogene, 28 (2009) 1792-1806.

[41] G. D'Alessandro, M. Catalano, M. Sciaccaluga, G. Chece, R. Cipriani, M. Rosito, A. Grimaldi, C. Lauro, G. Cantore, A. Santoro, B. Fioretti, F. Franciolini, H. Wulff, C. Limatola, KCa3.1 channels are involved in the infiltrative behavior of glioblastoma in vivo, Cell Death Dis, 4 (2013) e773.

[42] A. Girault, J. Chebli, A. Prive, N.T. Trinh, E. Maille, R. Grygorczyk, E. Brochiero, Complementary roles of KCa3.1 channels and beta1-integrin during alveolar epithelial repair, Respir Res, 16 (2015) 100. [43] T. Ben-Kasus Nissim, X. Zhang, A. Elazar, S. Roy, J.A. Stolwijk, Y. Zhou, R.K. Motiani, M. Gueguinou, N. Hempel, M. Hershfinkel, D.L. Gill, M. Trebak, I. Sekler, Mitochondria control store-operated $\mathrm{Ca}(2+)$ entry through $\mathrm{Na}(+)$ and redox signals, EMBO J, 36 (2017) 797-815.

[44] A.B. Parekh, Mitochondrial regulation of store-operated CRAC channels, Cell Calcium, 44 (2008) 6-13.

[45] U. De Marchi, N. Sassi, B. Fioretti, L. Catacuzzeno, G.M. Cereghetti, I. Szabo, M. Zoratti, Intermediate conductance Ca2+-activated potassium channel (KCa3.1) in the inner mitochondrial membrane of human colon cancer cells, Cell Calcium, 45 (2009) 509-516.

[46] N. Hempel, M. Trebak, Crosstalk between calcium and reactive oxygen species signaling in cancer, Cell Calcium, 63 (2017) 70-96.

[47] Y. Wang, F. Lei, W. Rong, Q. Zeng, W. Sun, Positive feedback between oncogenic KRAS and HIF1alpha confers drug resistance in colorectal cancer, Onco Targets Ther, 8 (2015) 1229-1237.

[48] B. Kong, C. Qia, M. Erkan, J. Kleeff, C.W. Michalski, Overview on how oncogenic Kras promotes pancreatic carcinogenesis by inducing low intracellular ROS levels, Front Physiol, 4 (2013) 246.

[49] S. Tao, S. Wang, S.J. Moghaddam, A. Ooi, E. Chapman, P.K. Wong, D.D. Zhang, Oncogenic KRAS confers chemoresistance by upregulating NRF2, Cancer Res, 74 (2014) 7430-7441.

[50] H. Yang, S. Xiang, A. Kazi, S.M. Sebti, The GTPase KRAS suppresses the $p 53$ tumor suppressor by activating the NRF2-regulated antioxidant defense system in cancer cells, J Biol Chem, 295 (2020) 30553063.

[51] R. Rapetti-Mauss, O. Soriani, H. Vinti, C. Badens, H. Guizouarn, Senicapoc: a potent candidate for the treatment of a subset of hereditary xerocytosis caused by mutations in the Gardos channel, Haematologica, 101 (2016) e431-e435. 


\section{Figures and Legends}

Figure 1

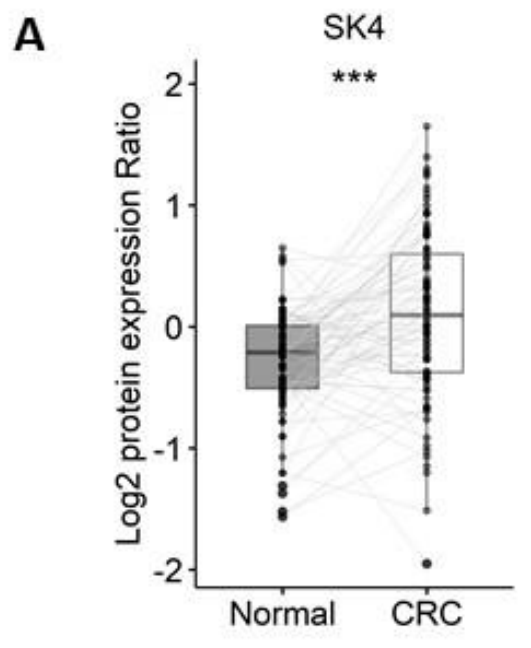

B

C

TP53

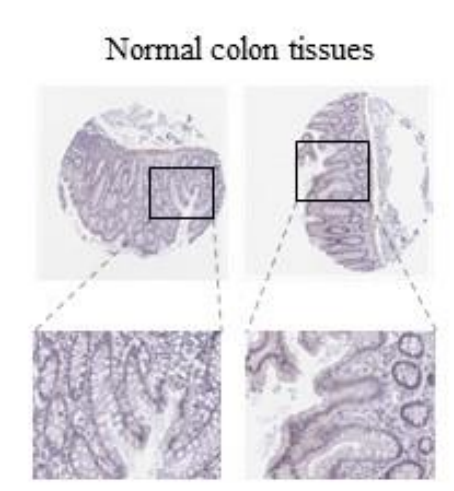

Colorectal cancer tissues

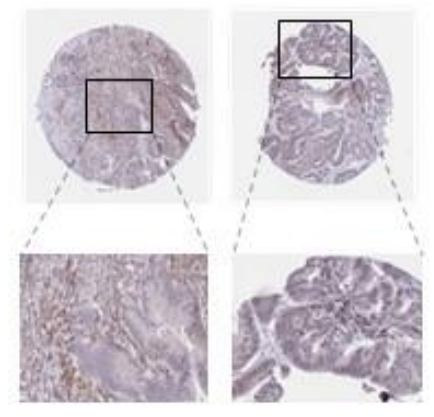

D

BRAF

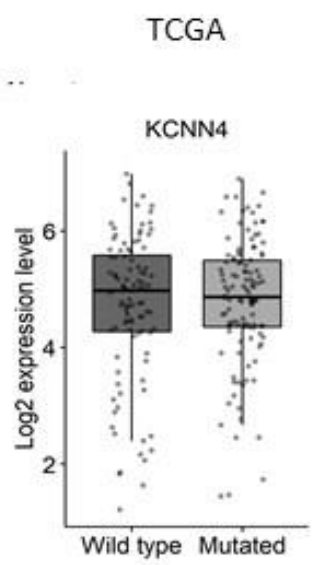

GSE39582

TCGA

GSE39582

$\mathrm{KCNN} 4$

KCNN4

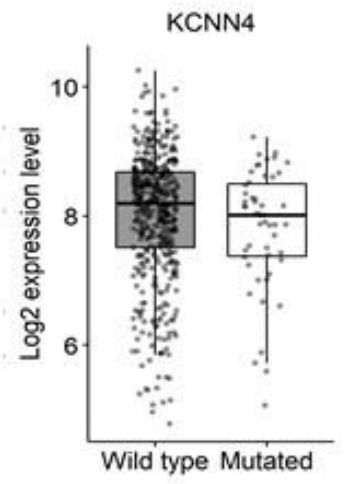

E
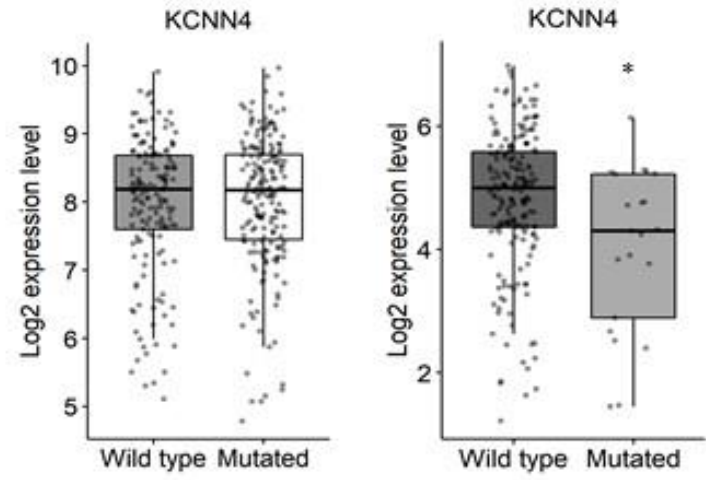

KRAS
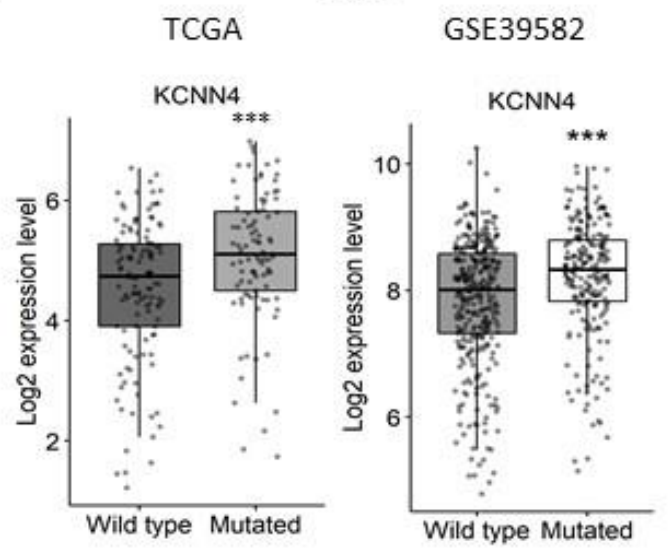

F
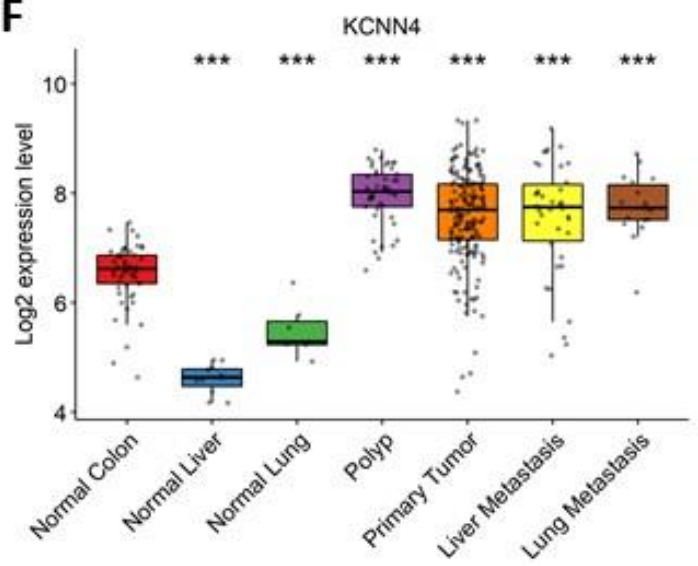
Figure 1. SK4 expression in colorectal cancer. (A) SK4 protein expression in colon cancer and adjacent normal tissues from the CPTAC data portal. Wilcoxon's signed-rank test was used to compare cancer tissues to their normal counterparts. (B) Immuno-histochemical staining of SK4 in normal colorectal and tumor tissues. Images were downloaded from http://www.proteinatlas.org. (C-E) KCNN4 expression profile in colorectal cancer according to the mutational status of TP53 (C), BRAF (D), and KRAS (E) genes. Student's $t$-test was used to compare KCNN4 expression between mutated and wild-type CRC tissues $(* \mathrm{p}<0.05$, *** $\mathrm{p}<0.001$ ). (F) Boxplot showing the expression of KCNN4 in primary and metastatic CRC tissues alongside normal tissues in the GSE41258 dataset. Student's t-test was used to compare KCNN4 expression between normal liver $(\mathrm{N}=11)$, normal lung $(\mathrm{N}=7)$, polyps $(\mathrm{N}=45)$, primary tumor $(\mathrm{N}=183)$, liver metastasis $(\mathrm{N}=38)$, lung metastasis $(\mathrm{N}-18)$, and normal Colon $(\mathrm{N}=53)$ $(* * *: \mathrm{p} \leq 0.001)$. 
Figure 2

A

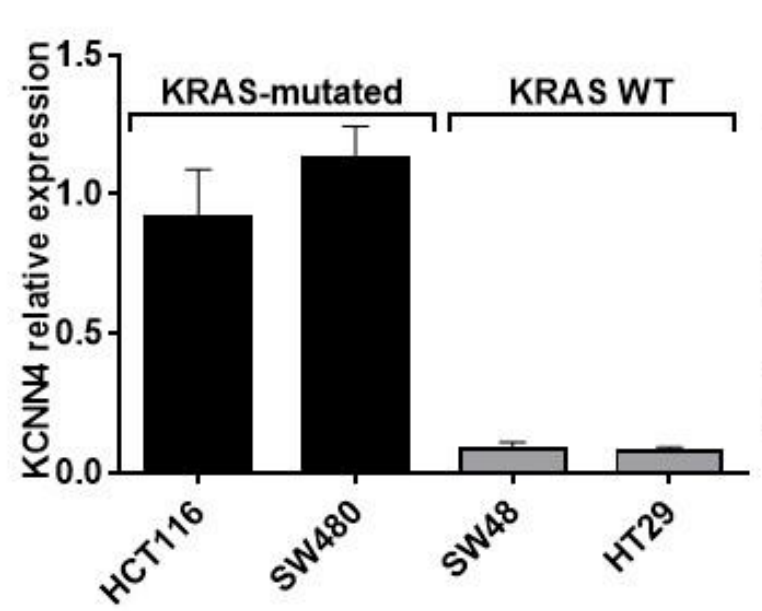

C
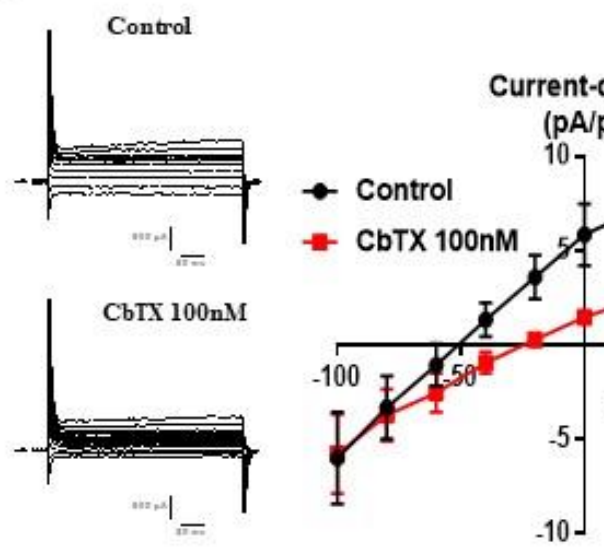

D

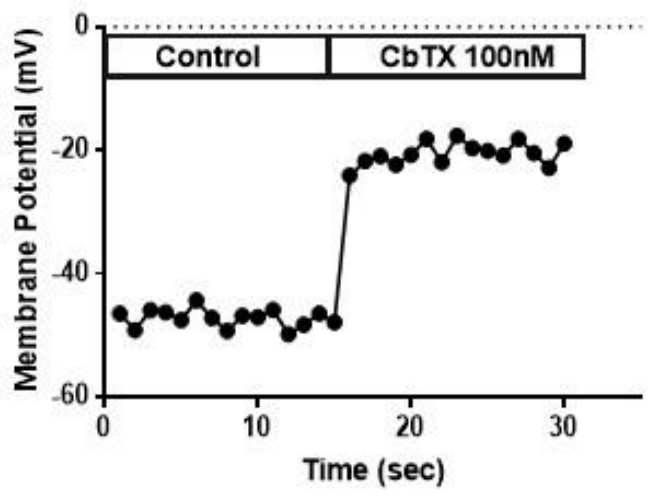

B

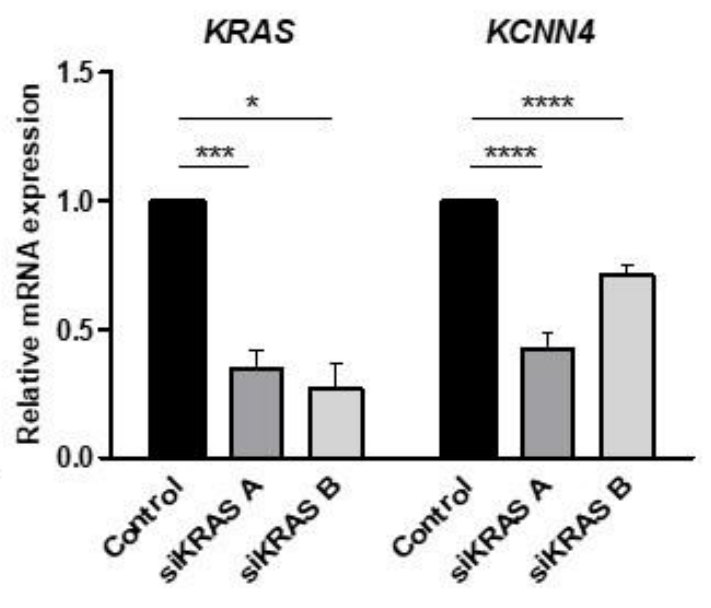




\section{Figure 2. SK4 expression and effect of charybdotoxin on CRC cell lines.}

(A) KCNN4 mRNA expression level in SW480, HCT116, SW48 and HT29 cells. KCNN4 expression for each cell line was measured by RT-qPCR. (N=3-6). (B) KRAS and KCNN4 expression in HCT116 cells after transfection with two siRNAs targeting KRAS compared to non-targeting control siRNA. Mann-Whitney test $(* * * \mathrm{p}<0.001)(\mathrm{N}=3)$. SK4 channel activity in HCT116 cells: 100nM of Charybdotoxin were used to inhibit SK4 activity (N=6). (C) Left panel: Examples and macroscopic currents recorded in HCT116 following voltage-pulses from -100 to $+100 \mathrm{mV}$. Recordings were performed using the whole-cell configuration of patchclamp technique. Right panel: Histogram showing SK4 inward rectification current inhibition by charybdotoxin at $0 \mathrm{mV}(\mathrm{N}=6)$. Mann-Whitney test $(* * \mathrm{P}<0,01)$. (D) (left) Example of membrane potential recorded using the patch-clamp technique in current-clamp mode in control condition (treated with Niflumic acid (NFA) $100 \mu \mathrm{M}$ ) followed charybdotoxin $100 \mathrm{nM}$ application. (right) Histogram showing membrane potential variations observed between NFA and charybdotoxin conditions. Mann-Whitney test $(* \mathrm{P}<0,05, \mathrm{~N}=7)$. 
A
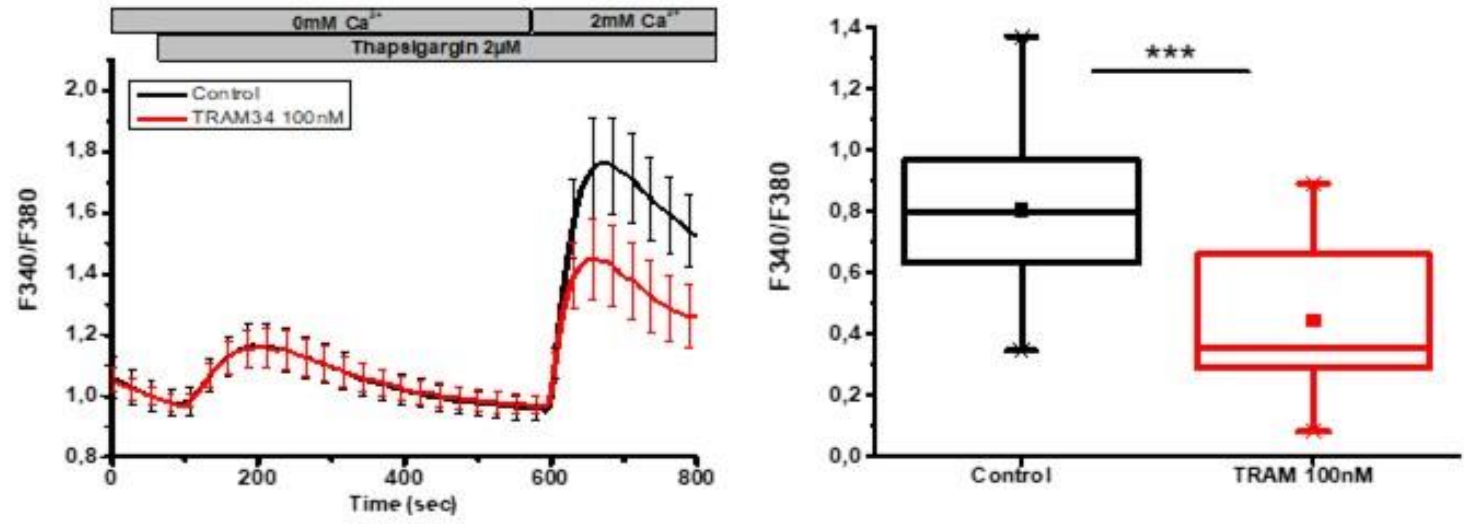

B
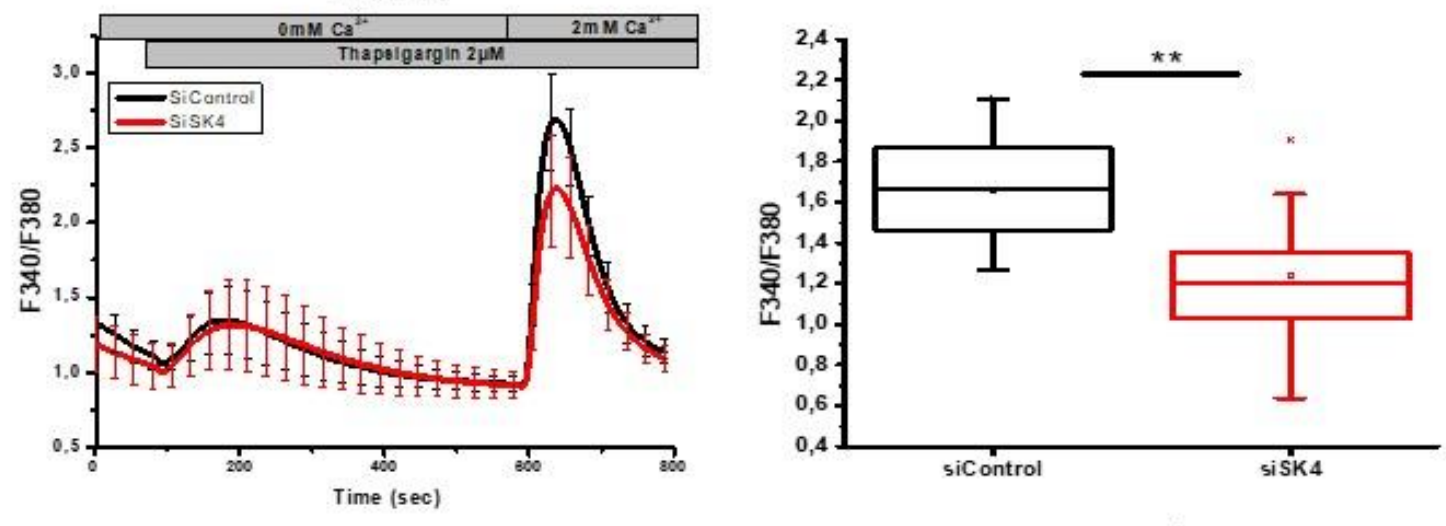

C
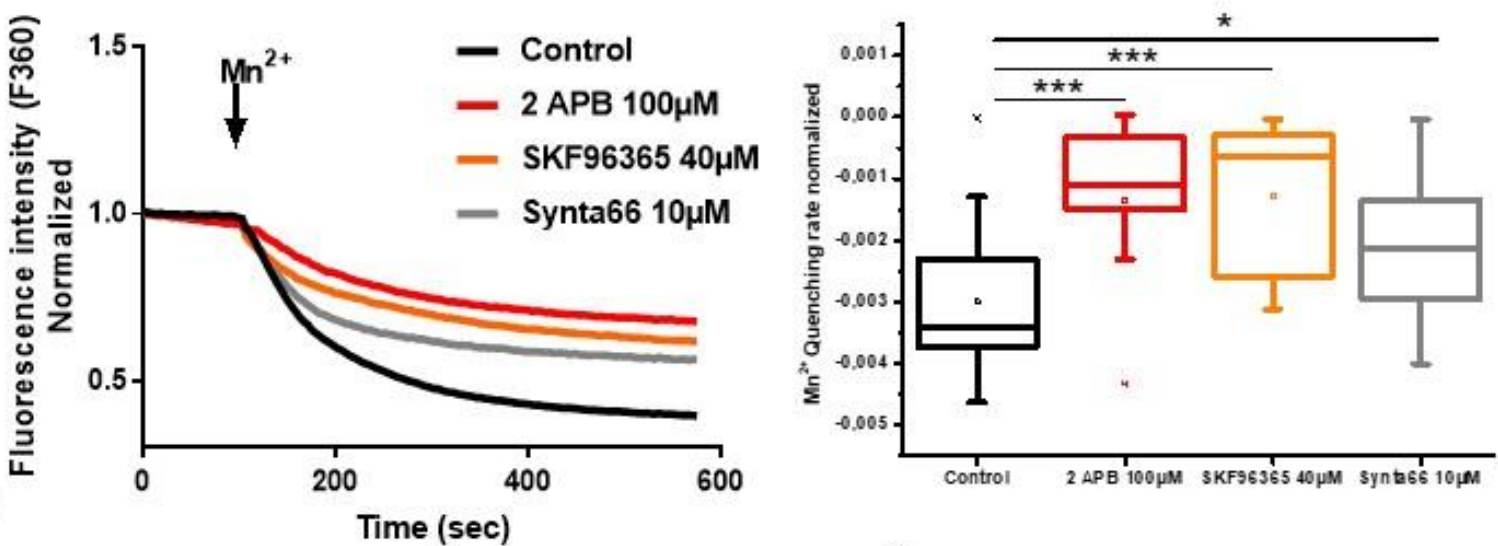

D
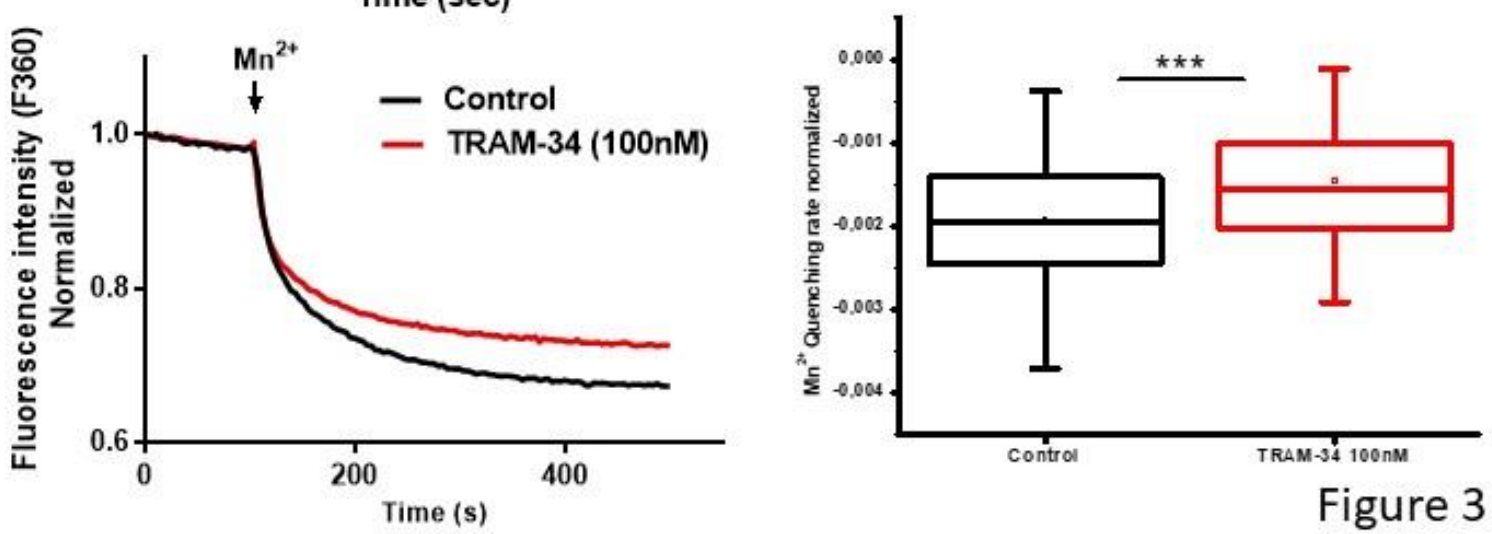

Figure 3 


\section{Figure 3. SK4 inhibition reduces Ca2+ entry in HCT116.}

(A-B) Effect of SK4 inhibition by TRAM-34 (100nM) (A) or siKCNN4 B (B) on SOCE in HCT116 cells. Left panels: Fluorescence measurement of SOCE induced by TG in TRAM-34 or siKCNN4. Right panels: Fluorescence measurement of SOCE induced by TG in TRAM-34 and siKCNN4 conditions compared to control on the relative fluorescence of HCT116 cells loaded with Fura2-AM (***: p<0.001) ( $N=4$ ( $n=18-20$ per condition)). (C) Effect of Orai1 and TRPC1 inhibition on CCE using Mn2+ quenching assay. Left: The effects of 2-ABP $(10 \mu \mathrm{M})$, SKF96365 $(40 \mu \mathrm{M})$ and Synta66 $(10 \mu \mathrm{M})$ on Mn2+ quenching rate $(* * *: \mathrm{P}<0.001)$. Right: Effects of 2-ABP, SKF96365 and Synta66 on normalized Mn2+ quenching slope ( $* * * \mathrm{P}<0.001)$ ( $N=4, n=29-23$ per condition). (D) Effect of SK4 inhibition on CCE using Mn2+ quenching assay: Representative intensity of TRAM-34 (100 nM) on Mn2+ quenching rate. Effects of TRAM-34 on normalized Mn2+ quenching slope (***P $<0.001$, Mann-Whitney test, $\mathrm{N}=5$, $n=76$ per condition). 
Figure 4
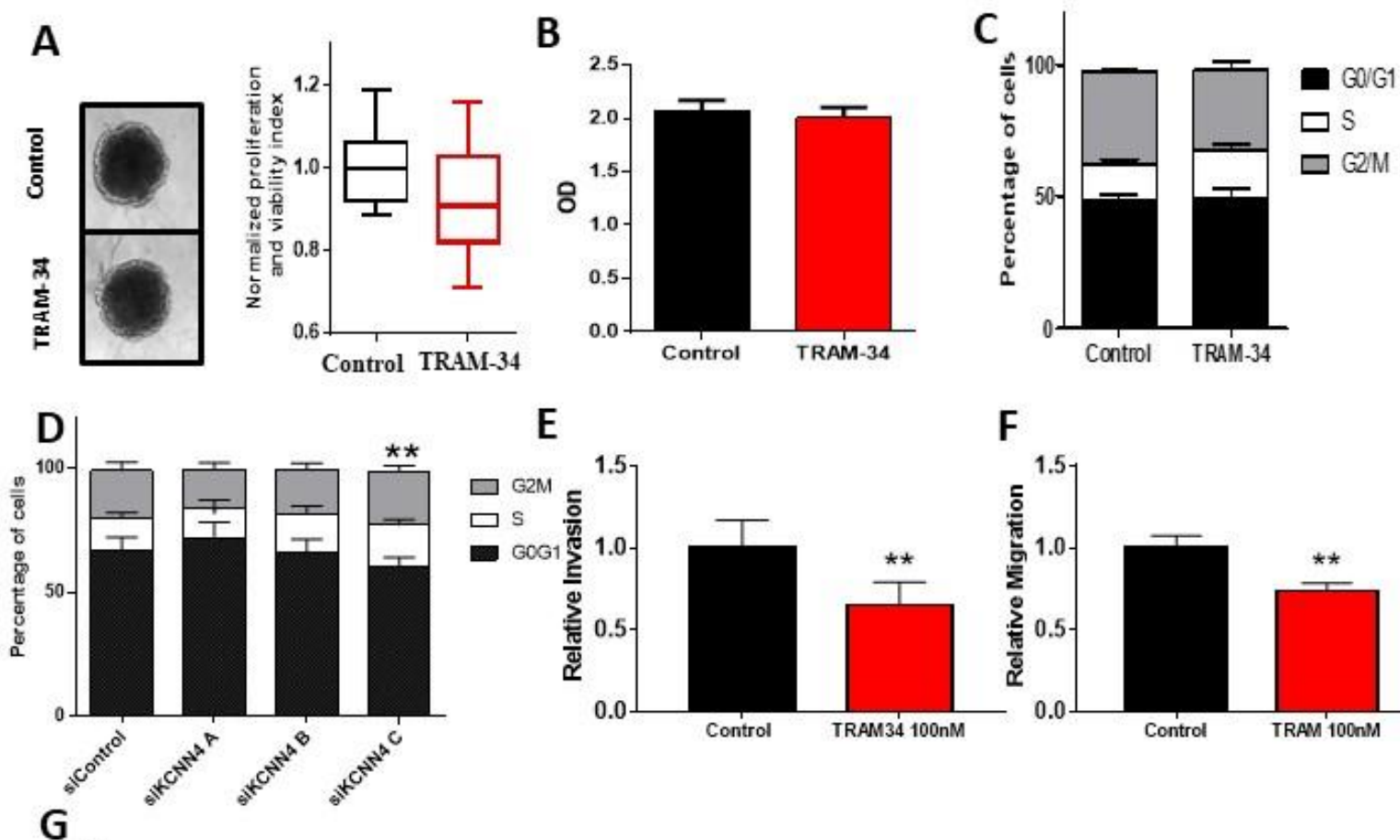

E
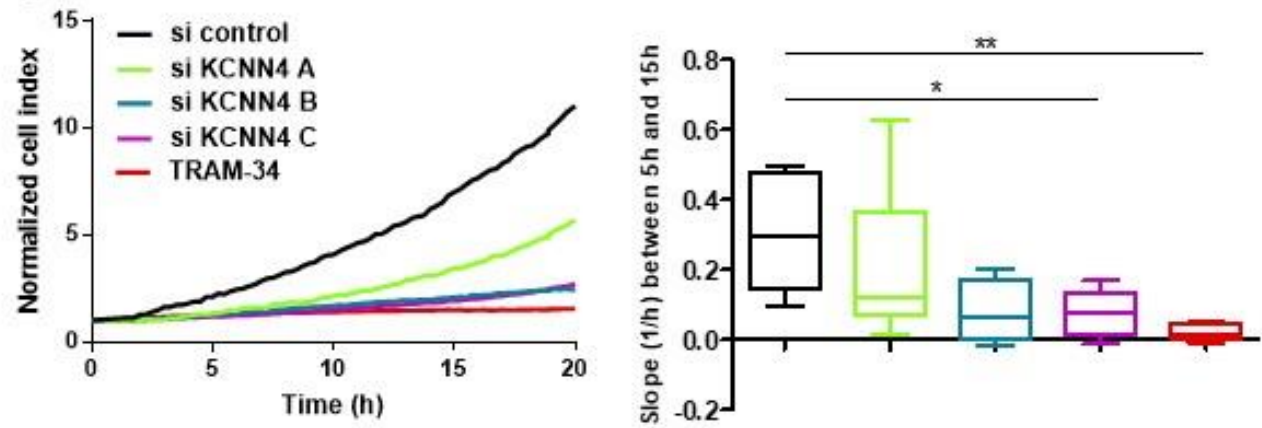

$\square$ si control

$\square$ si KCNN4 A

$\square$ si KCNN4 B

$\square$ si KCNN4 C

$\square$ TRAM-34 
Figure 4. Effects of SK4 inhibition on cell viability, proliferation and migration.

(A) Representative images of spheroids (left) and boxplot (right, $\mathrm{N}=4, \mathrm{n}=16$ ) showing the effect of SK4 inhibition by TRAM-34 (100nM) on HCT116 proliferation in 3D culture model. (B) Effect of SK4 inhibition by TRAM-34 (100nM) on the proliferation of HCT116 cells in 2D culture. Cell proliferation was measured using MTT assay. (C-D) Effect of SK4 inhibition by TRAM-34 (C) and siRNAs targeting KCNN4 (D) on the cell cycle of HCT116 cells. Untreated cells or cells transfected by non-targeting siRNAs were used as control, respectively. Cell cycle was analysed by flow cytometry following propidium iodide staining. (E-F) Effect of TRAM34 on cell invasion (E) and migration (F) in HCT116 $(\mathrm{N}=3, \mathrm{n}=9)$. Cell migration and invasion were analyzed using Boyden chamber assay $(\mathrm{N}=3, \mathrm{n}=9)$. (G) Effect of SK4 inhibition by TRAM-34 and siRNAs against KCNN4 on cell migration in real-time condition. (Left) Curves showing the kinetics of normalized cell-index values, measured by xCELLigence cell migration assay. (Right) Boxplots showing the slopes of normalized cell-index from various conditions. Slopes were calculated from data measures between $5 \mathrm{~h}$ and $15 \mathrm{~h}$ time points. For all experiments except cell cycle and xCELLigence, Mann-Whitney test was used to compare various conditions to respective controls. For cell cycle, two-way ANOVA followed by Student's t-test was used to compare phases-proportions from various conditions to respective controls. For xCELLigence, one-way ANOVA followed by Student's t-test was used to compare various conditions to control. ( $\mathrm{p} \leq 0.05, * *: \mathrm{p} \leq 0.01, * * *: \mathrm{p} \leq 0.001, \mathrm{~N}=3$ ( $\mathrm{n}=5-9$ per condition). 
Figure 5

A

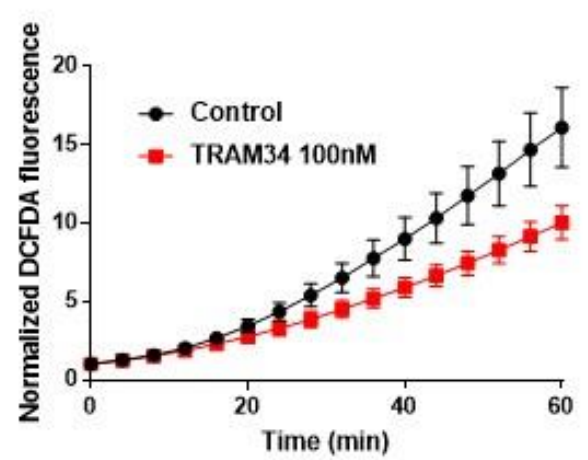

C

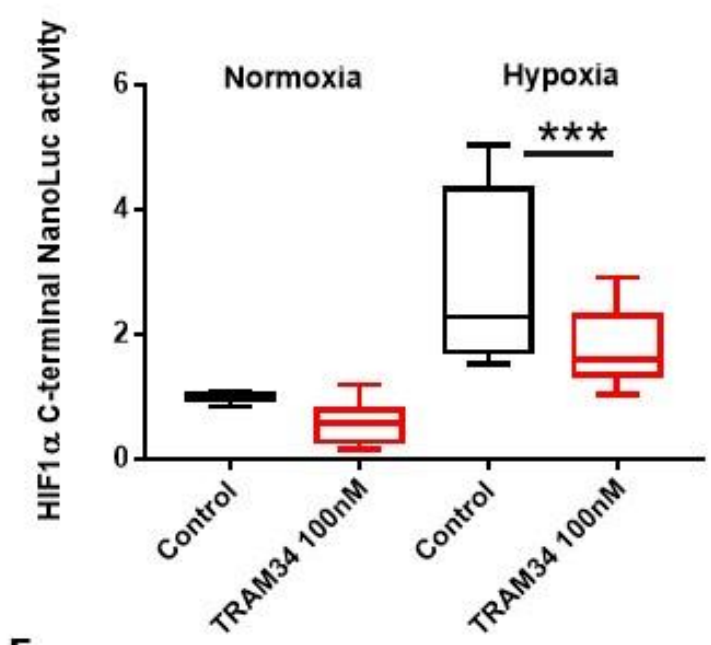

E

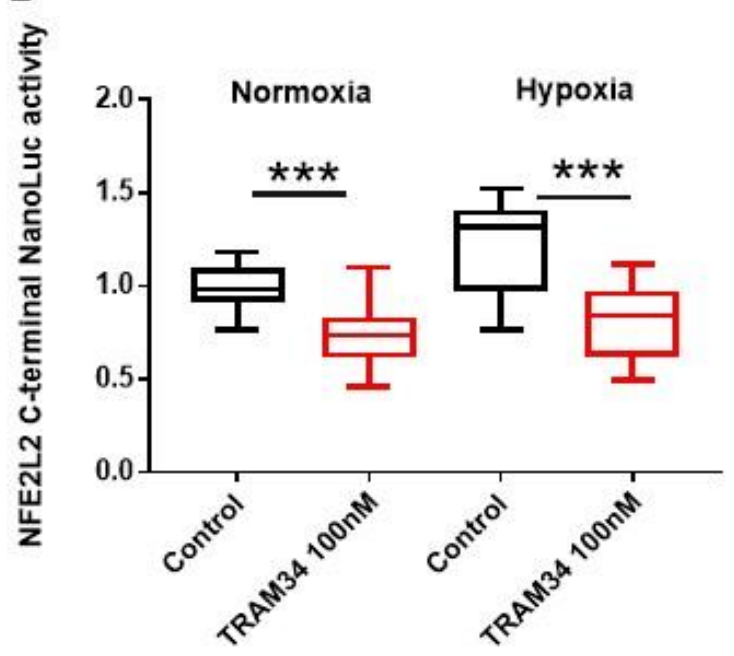

B

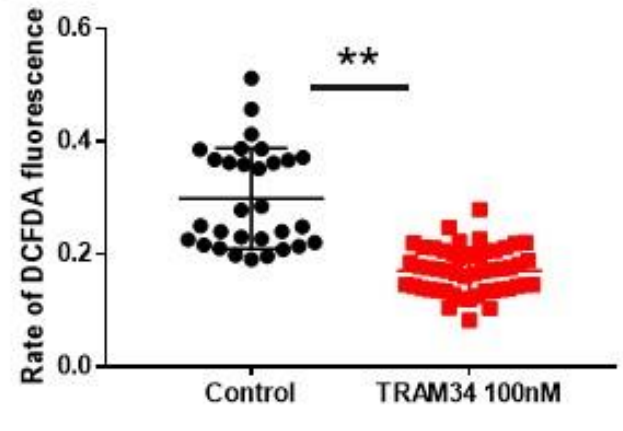

D

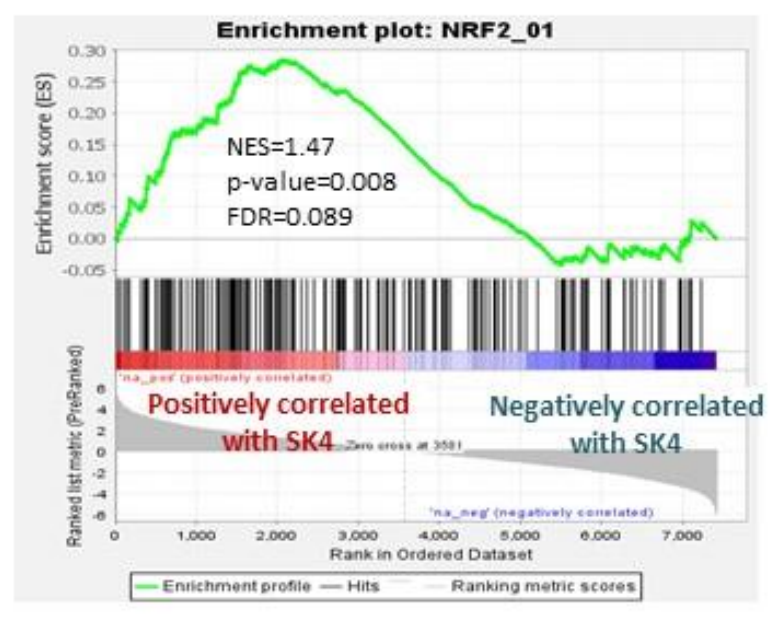


Figure 5. Effect of SK4 inhibition on intracytoplasmic ROS, NRF2 expression and HIF1a stabilization.

(A) Effect of SK4 inhibition by TRAM-34 (100nM) on intracytoplasmic ROS. Left: Curves representing ROS production kinetics as assessed by DCFDA. (B) ROS production rates in TRAM-34 treated and control HCT116. ( $=5, n=30-51$, Mann-Whitney test, **: $\mathrm{p}<0.01)$ (C) Effect of SK4 inhibition by TRAM-34 (100nM) on HIF1 $\alpha$ stabilization. HIF1 $\alpha$ expression was detected by Nanoluc activity under normoxia and hypoxia $(1 \% \mathrm{O} 2)$ conditions $(\mathrm{N}=4, \mathrm{n}=14$ per condition, Mann-Whitney test, **: $\mathrm{p}<0.01$; ***: $\mathrm{p}<0.001$ ). (D) Geneset enrichment analysis (GSEA) of NRF2 target genes in 96 primary CRC tissues from the CPTAC proteomic dataset. (E) Effect of SK4 inhibition by TRAM-34 (100nM) on NRF2 expression was detected by Nanoluc activity (NFE2L2 C-terminal NanoLuc) under normoxia and hypoxia conditions $(\mathrm{N}=4, \mathrm{n}=13-20$ per condition, Mann-Whitney test $* * *: \mathrm{p}<0.001)$. 


\section{Supplementary Figure S1}

HT29
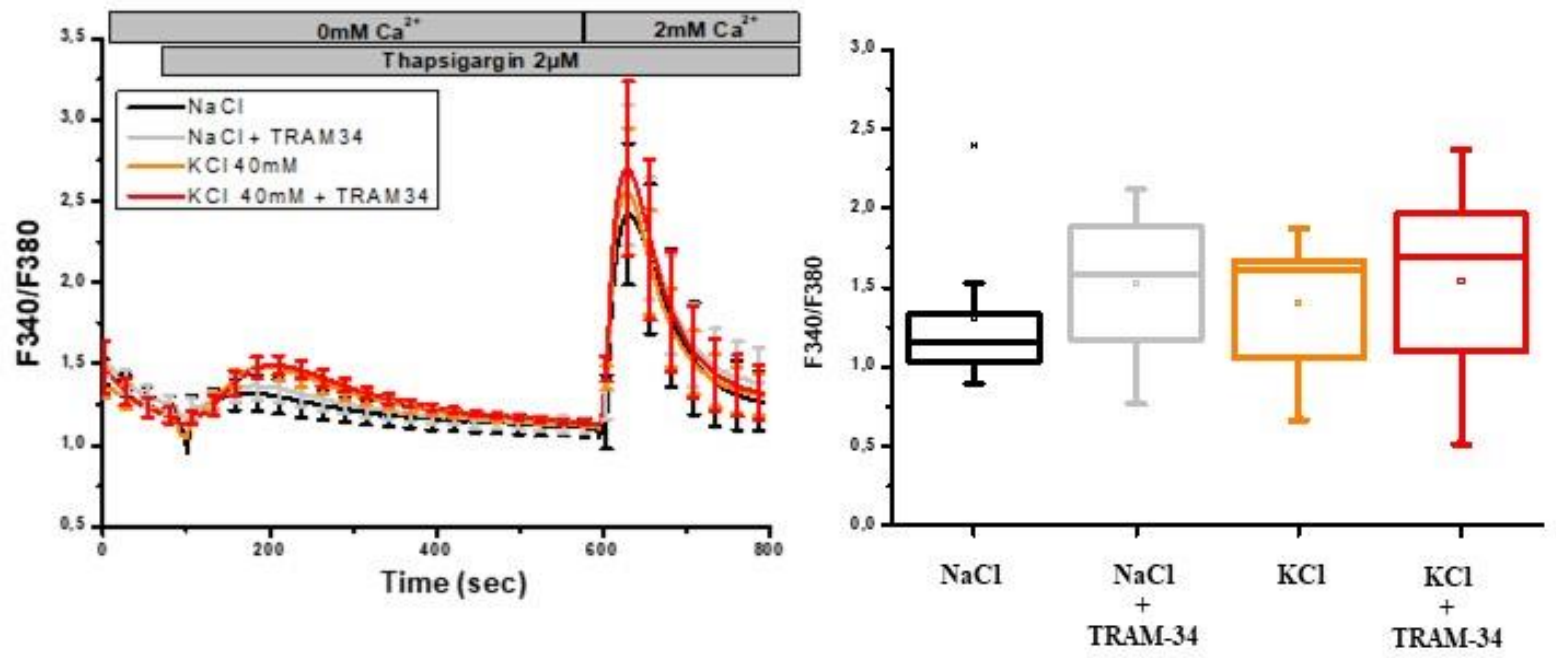

HCT116
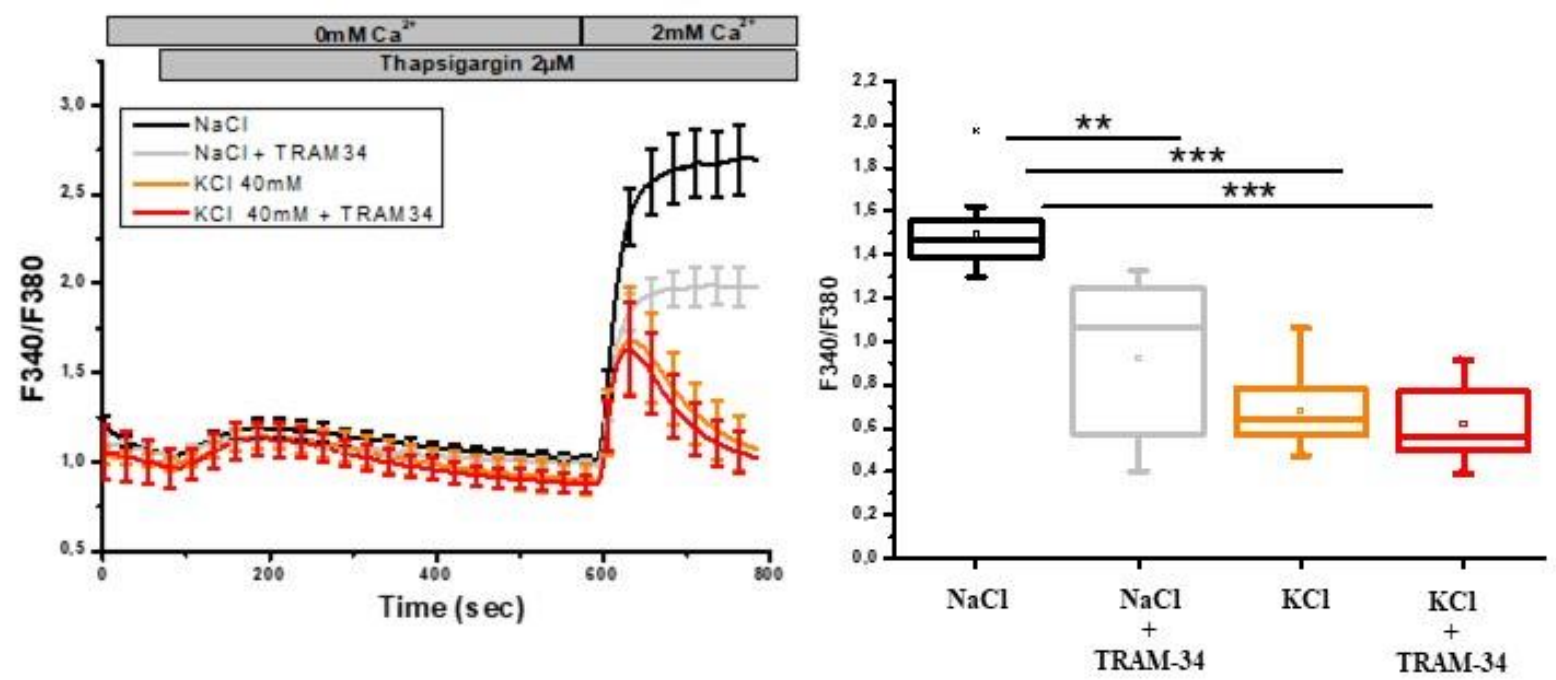

\section{Supplementary Figure S1}

Effect of SK4 inhibition by TRAM-34 (100nM) with or without addition of $40 \mathrm{mM} \mathrm{KCl}$ or 40 $\mathrm{mM} \mathrm{NaCl}$ in PSS (140 mM NaCl, $4 \mathrm{mM} \mathrm{KCl)} \mathrm{on} \mathrm{SOCE} \mathrm{in} \mathrm{HT29} \mathrm{(up)} \mathrm{or} \mathrm{HCT116} \mathrm{cells} \mathrm{(down).}$ Left panels: Fluorescence measurement of SOCE induced by TG in TRAM-34 or charybdotoxin. Right panels: Fluorescence measurement of SOCE induced by TG in TRAM34 conditions compared to control $\mathrm{NaCl}$ on the relative fluorescence of HT29 (up) or HCT116 (down) loaded with Fura2-AM ((**: p<0.01; ***: p<0.001, Mann-Whitney test) (HT29: N =4 and $n=14-16$; HCT116, N=3 and $n=9-16)$. 


\section{Supplementary Figure S2}

A

HCT116
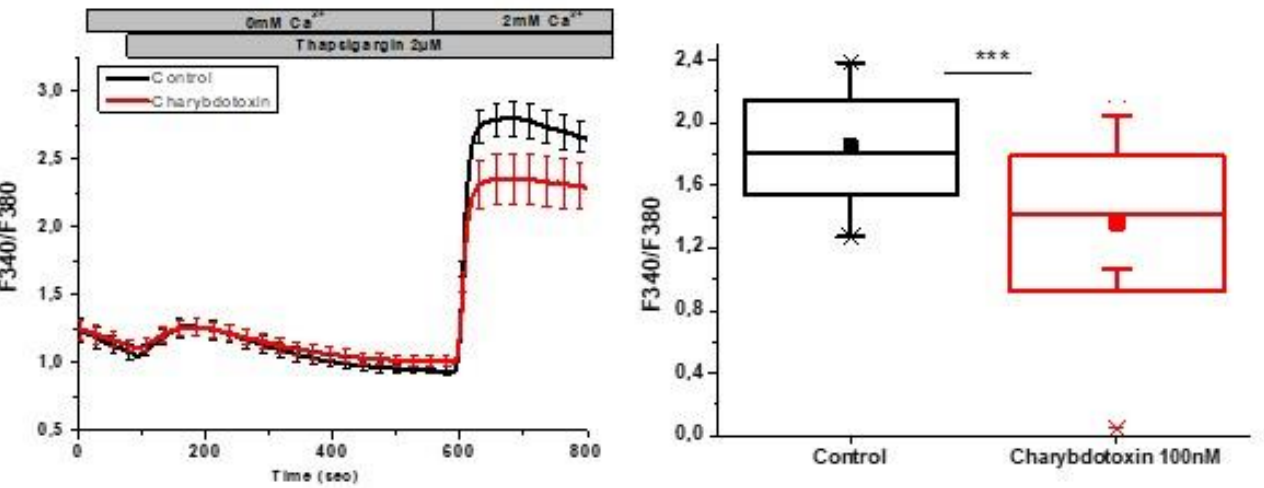

B

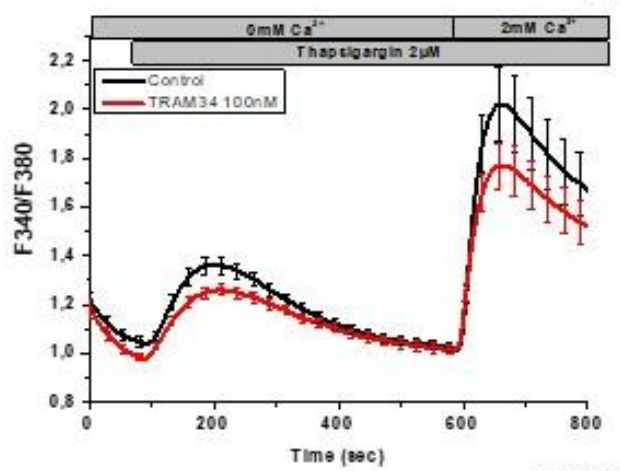

HT29

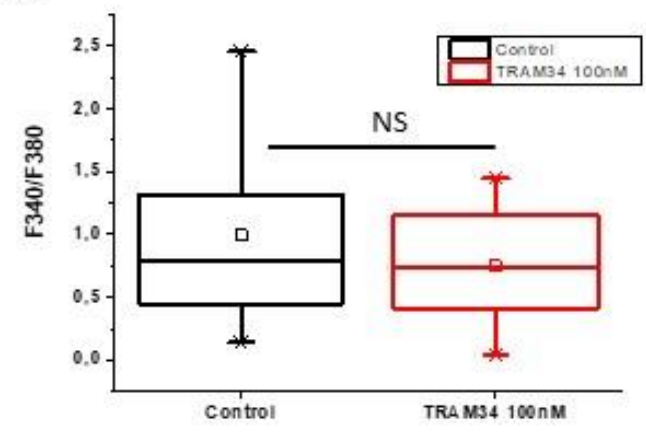

C
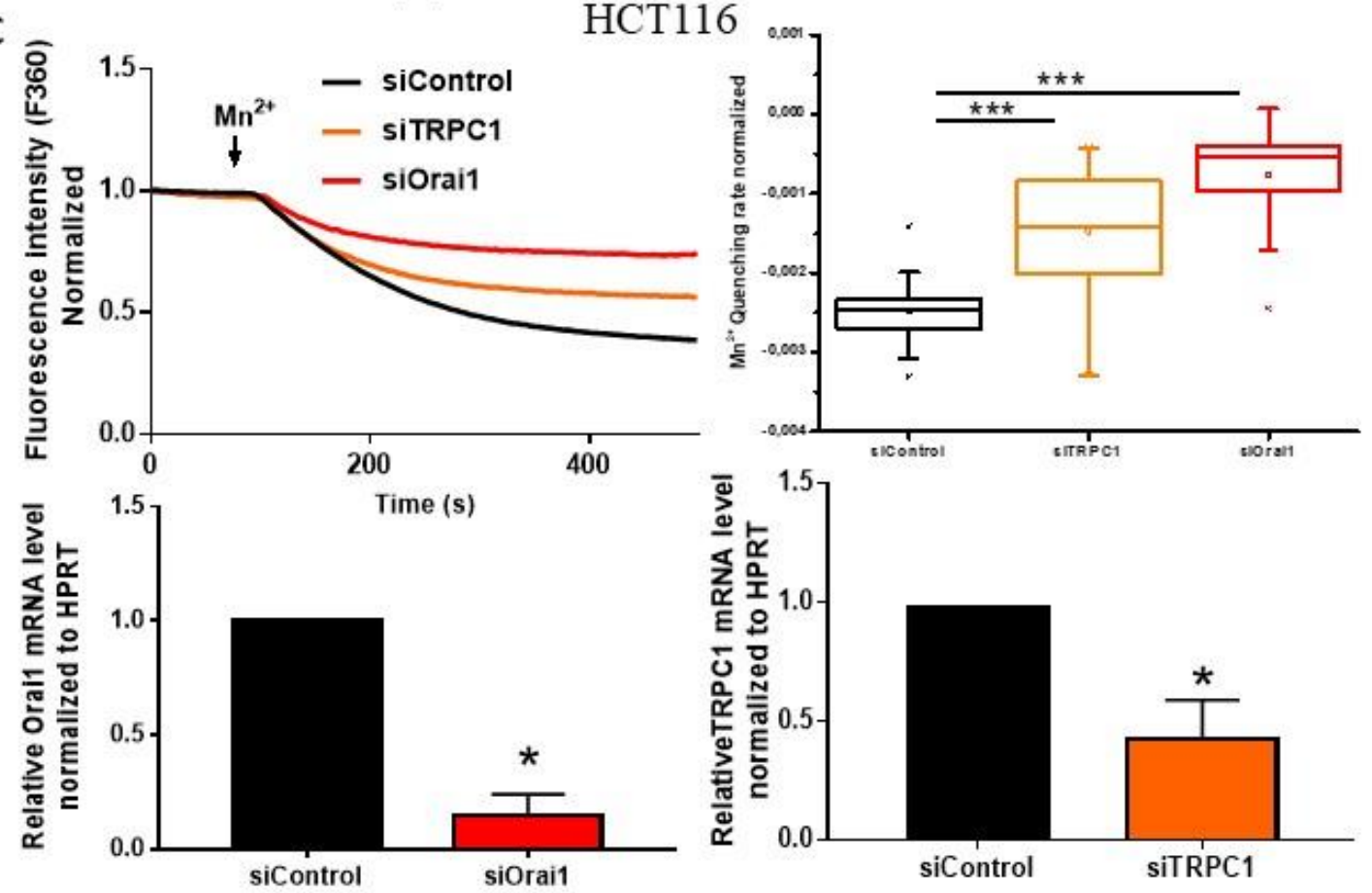


\section{Supplementary Figure S2}

A) HCT116. Left panel: Fluorescence measurement of SOCE induced by TG. SK4 inhibition was done by charybdotoxin $(100 \mathrm{nM}) \mathrm{N}=4$ ( $\mathrm{n}=19$ per condition). Right: Histograms showing the effect of charybdotoxin $(100 \mathrm{nM})$ on SOCE compared to control on the relative fluorescence of cells loaded with Fura2-AM (*** $\mathrm{P}<0.001$, Mann-Whitney test).

B) HT29. Left panel: Fluorescence measurement of SOCE induced by TG. SK4 inhibition was done by TRAM-34 (100 nM). Right: Histograms showing the effect of TRAM-34 (100nM) on SOCE compared to control on the relative fluorescence of cells loaded with Fura2-AM (ns) ( $N=4, n=24$ per condition, Mann-Whitney test).

C) HCT116. Fluorescence measurement of SOCE induced by TG. Orai1/TRPC1 inhibition were done by siRNA $N=4$ ( $n=43$ for SiControl, 31 for siOrai1, 26 for siTRPC1). Right: Histograms showing the effect of siOrail and siTRPC1 on SOCE compared to control on the relative fluorescence of cells loaded with Fura2-AM (*** $\mathrm{P}<0.001$, Mann-Whitney test with control).

D) qPCR validation of siRNA against Orai1 and TRPC1 $(\mathrm{N}=4, * \mathrm{P}<0.05$, Mann-Whitney test with control) 
Supplementary Figure S3 Lovo

A
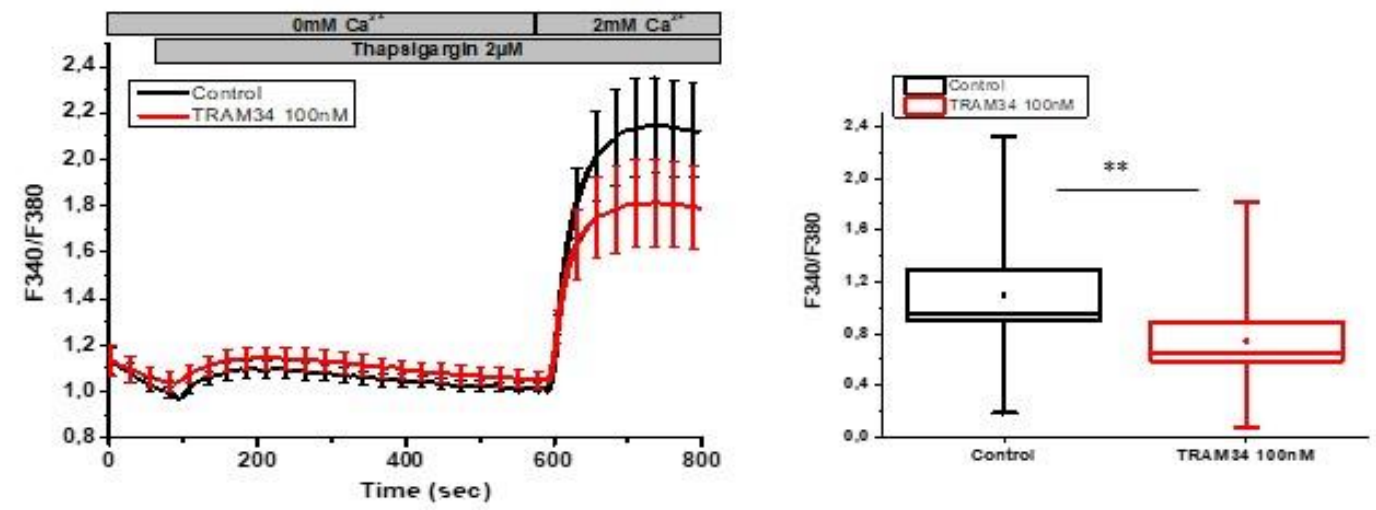

B
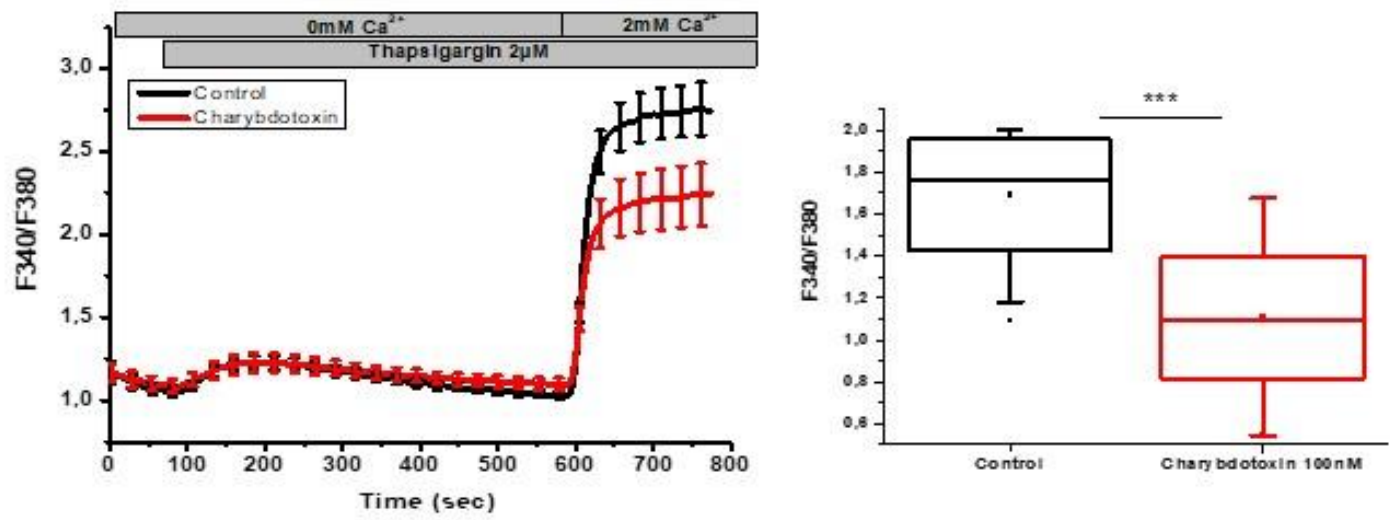

C
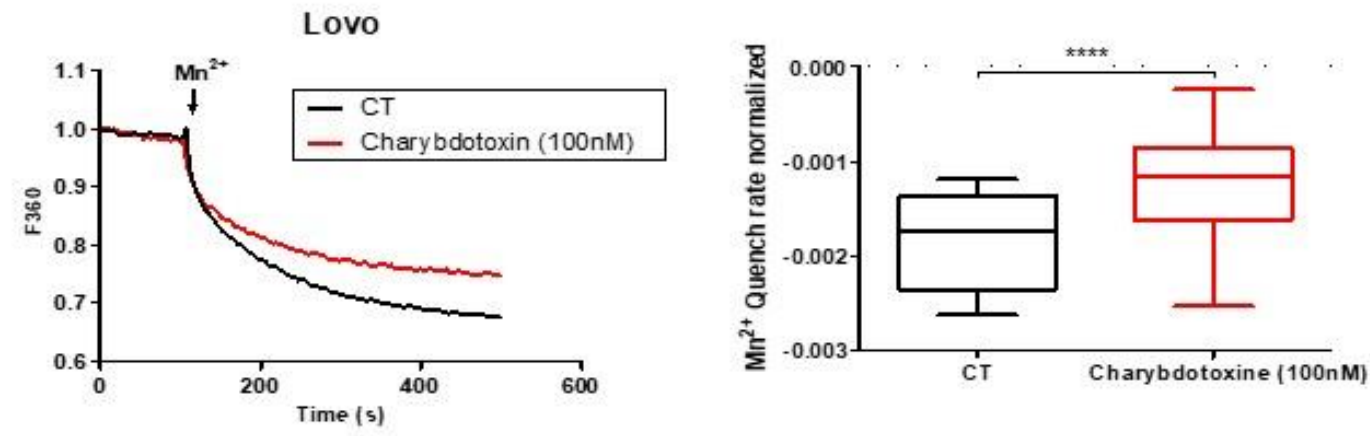

D
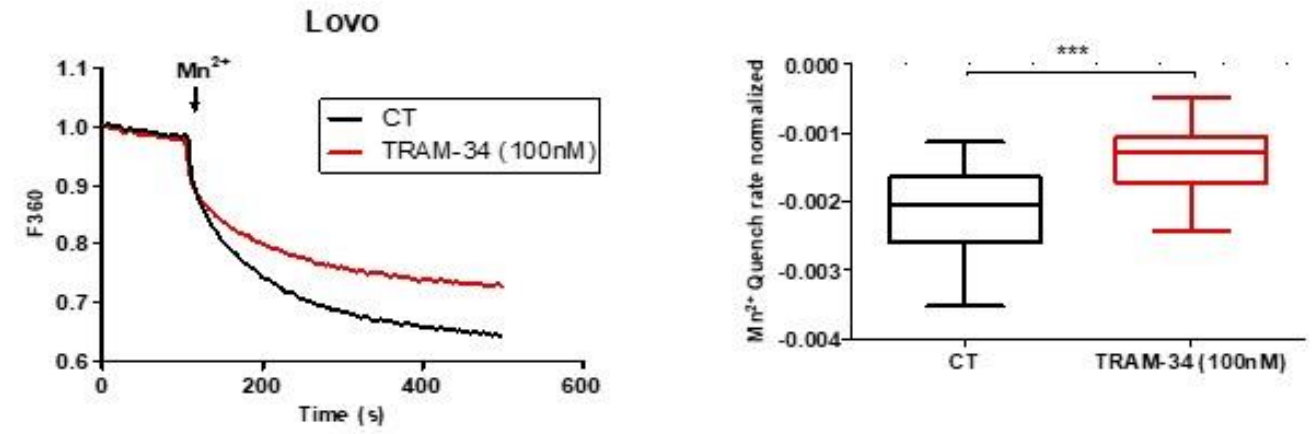


\section{Supplementary Figure S3: SK4 inhibition reduces Ca2+ entry in Lovo.}

(A-B) Effect of SK4 inhibition by TRAM-34 (100nM) (A) or charybdotoxin (100nM) (B) on SOCE in Lovo cells. Left panels: Fluorescence measurement of SOCE induced by TG in TRAM-34 or charybdotoxin. Right panels: Fluorescence measurement of SOCE induced by TG in TRAM-34 conditions compared to control on the relative fluorescence of Lovo cells loaded with Fura2-AM ((**: p<0.01; ***: $\mathrm{p}<0.001)$ ( $N=3, n=16$ per condition). (C-D) Effect of SK4 inhibition on CCE using Mn2+ quenching assay: Left panels: The effects of TRAM$34(100 \mathrm{nM})$ or charybdotoxin $(100 \mathrm{nM})$ on $\mathrm{Mn} 2+$ quenching rate $(\mathrm{P}<0.001)(\mathrm{N}=4, \mathrm{n}=32$ per condition). Right panels: Effects of TRAM-34 on normalized Mn2+ quenching slope $(* * * \mathrm{P}<0.001$, Mann-Whitney test). 


\section{Supplementary Figure S4}

A
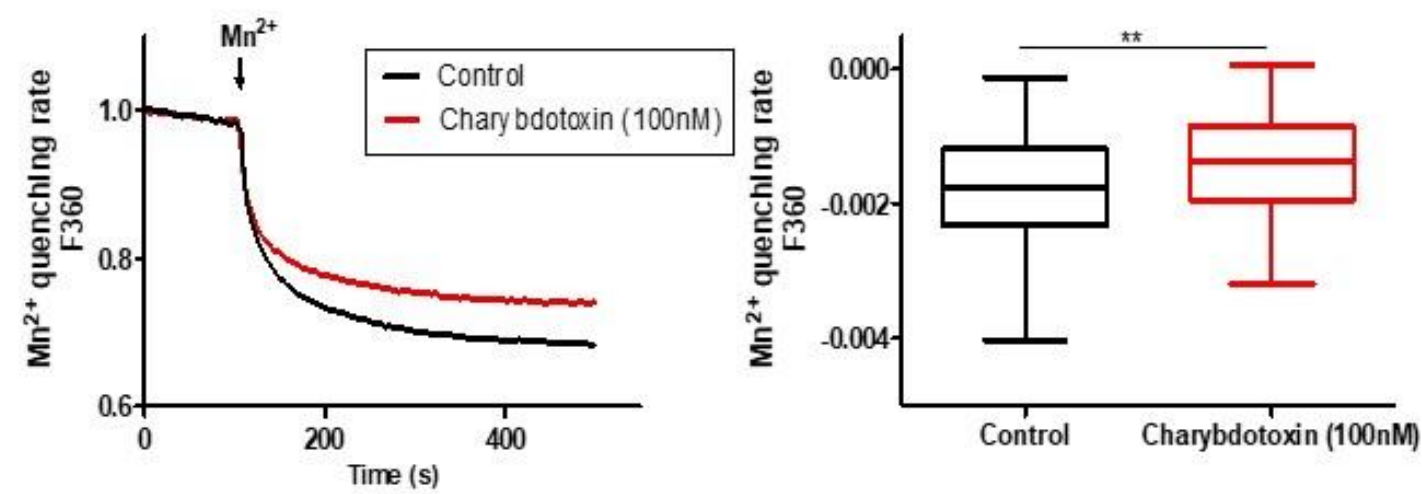

B
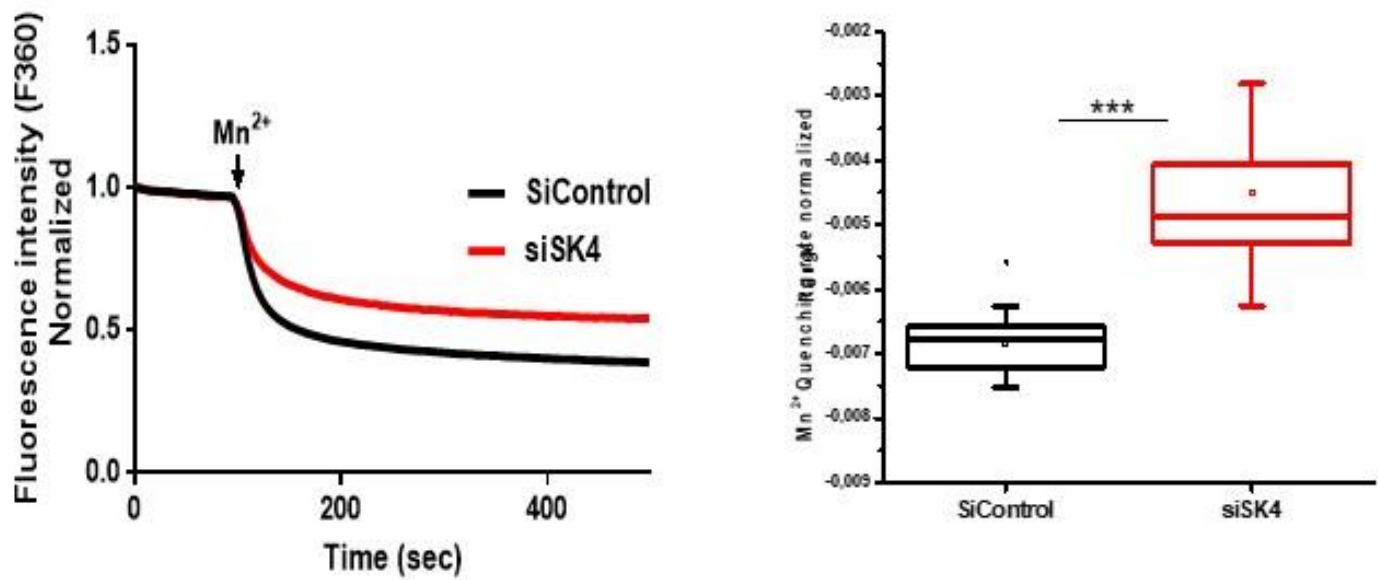

Supplementary Figure S4: SK4 inhibition reduces CCE in HCT116.

(A-B) Effect of SK4 inhibition by charybdotoxin (A) or siKCNN4 (B) on CCE using Mn2+ quenching assay in HCT116; respectively $N=5$ ( $n=88$ per condition) and $N=4(n=18-20$ per condition). Left panels: Fluorescence measurement of CCE induced by TG in TRAM-34 or charybdotoxin. Right panels: Fluorescence measurement of CCE in TRAM-34 conditions compared to control on the relative fluorescence of HCT116 cells on Mn2+ quenching rate. $(* *: \mathrm{p}<0.01 ; * * *: \mathrm{p}<0.001$, Mann-Whitney test). 


\section{Supplementary Figure S5}

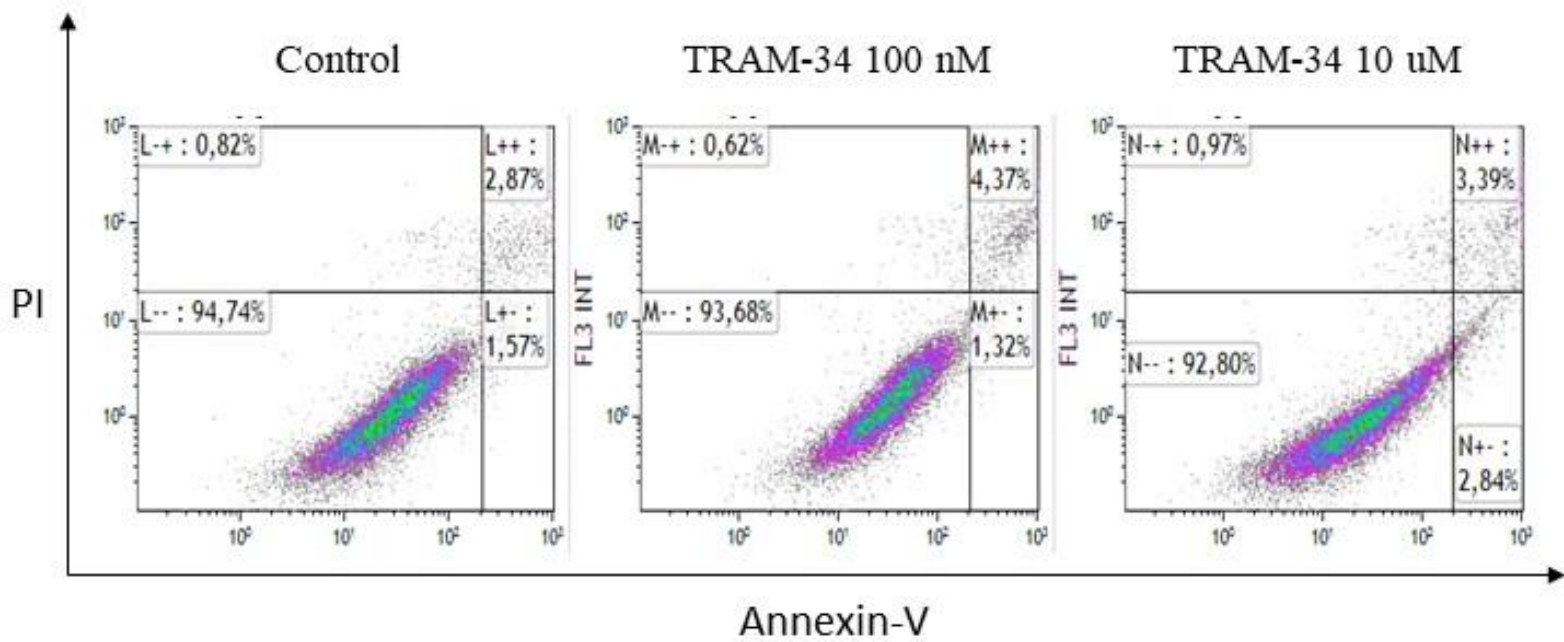

Supplementary Figure S5: Effect of SK4 inhibition by TRAM-34 on apoptosis induction. Representative histograms showing the effect of SK4 inhibition by TRAM-34 (100 nM and 10uM) on apoptosis induction in HCT116 compared to control. with annexin V-FITC and propidium iodide (PI). Alive cells are both Annexin V and PI negative. Early apoptotic cells are Annexin V positive and PI negative. Late apoptotic and necrotic cells are both Annexin V and PI positive. N=4 (ns, Mann-Whitney test, comparison with control) 
Supplementary Figure S6

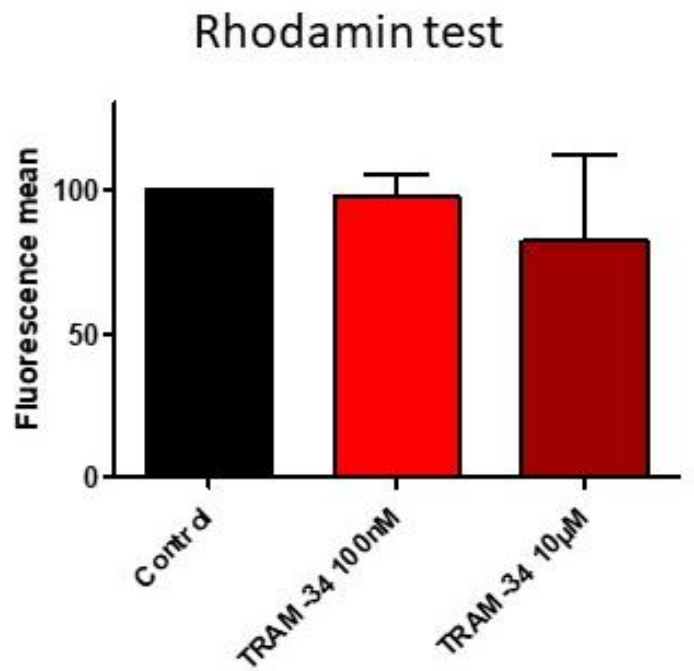

Supplementary Figure S6. Effect of SK4 inhibition by TRAM-34 on mitochondrial Ca2+. Mitochondrial $\mathrm{Ca} 2+$ rate was studied by rhodamine-2 staining. N=4 (ns, Mann-Whitney test, comparison with control). 